\title{
The Impact of School Strategies and the Home Environment on Home Learning Experiences During the COVID-19 Pandemic in Children With and Without Developmental Disorders
}

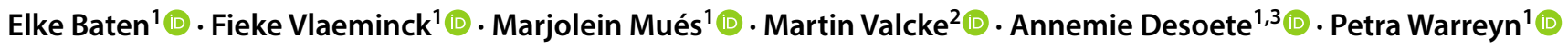

Accepted: 22 November 2021 / Published online: 11 January 2022

(c) The Author(s), under exclusive licence to Springer Science+Business Media, LLC, part of Springer Nature 2021

\begin{abstract}
Using the Opportunity-Propensity Model (Byrnes in Dev Rev 56:100911, 2020; Byrnes \& Miller in Contemp Educ Psychol 32(4);599-629, 2007), the current study investigated which factors helped predicting children's home learning experiences during the COVID-19 pandemic, thereby examining differences between children with (DD; $n=779$ ) and without (TD; $n=1443$ ) developmental disorders. MANCOVA results indicated more negative experiences for DD children and their parents. SEM-results revealed the alignment between different teachers and autonomous motivation in children as the most important predictors for the outcome variables. Less predictors were significant for DD as compared to TD children which suggests other factors are at play in the DD group. Limitations, strengths and suggestions for future research are being discussed, together with some implications for classroom practices and remote learning approaches.
\end{abstract}

Keywords Developmental disorders · Remote learning · Opportunity-Propensity Model · COVID-19 · School closures

As of the beginning of 2020, the coronavirus (COVID-19) pandemic (WHO, 2020) confronted the world with new and unknown challenges. For education, this meant that schools in many countries had to close on short notice (Haug et al., 2020). In Flanders, the Dutch speaking part of Belgium, for example, schools closed completely from mid-March until the beginning of June 2020. Teachers and school staff had to find new ways to communicate with their students and remote teaching became the new formal way of education. This sudden switch to home schooling led to challenges for both students and their families. From one day to the next, the daily school routine and the pre-structured school environment was replaced by students' home environment and parents suddenly became part-time educators,

Elke Baten

elke.baten@ugent.be

1 Department of Experimental Clinical and Health Psychology, Research in Developmental Disorders Lab, Ghent University, Henri Dunantlaan 2, 9000 Ghent, Belgium

2 Department of Educational Studies, Ghent University, Henri Dunantlaan 2, 9000 Ghent, Belgium

3 Artevelde University College, Voetweg 66, 9000 Ghent, Belgium while additionally coping with other (parental) worries and tasks, such as household chores, the care for other children, (tele)work and perhaps financial problems or work-loss due to the pandemic (Becker et al., 2020).

Consequently, the loss of daily structure and routine, and the switch to online learning may have been more challenging for some students compared to others, depending on individual differences such as the abovementioned parental availability (Dong et al., 2020), but also socioeconomic status (SES; Liu et al., 2020; Peng et al., 2019), ICT accessibility (Becker et al., 2020; Maity et al., 2021), and particular child characteristics (Becker et al., 2020). Studies comparing virtual and regular classrooms outside the context of the pandemic (e.g., Ahn \& McEachin, 2017; Fitzpatrick et al., 2020) already showed that well-performing children in regular classrooms kept performing well in virtual school environments, while vulnerable students who were already struggling with education, such as children with a learning disorder or another developmental disorder, were rather negatively impacted by virtual schooling (Reich et al., 2020).

With this in mind, the focus of the current study was to examine the impact of remote learning in the context of the COVID-19 pandemic on children with developmental disorders (DD) as compared to their typically developing (TD) peers. Neurodevelopmental disorders 
are characterized by early onset deficits in the development of language, communication, cognitive, motor and/or social skills. These disorders have an impact on several life domains throughout the lifespan, leading to impaired daily life functioning. Even though different heterogeneous DD are described in the Diagnostic and Statistical Manual of Mental Disorders - 5th Edition (DSM-5;American Psychiatric Association, 2013), comorbidity is often seen among them. This co-occurrence often makes it hard to differentiate between the several DD (Dewey, 2018).

Children with DD are potentially more vulnerable for the negative consequences of the remote learning situation since their disorder already makes it challenging in regular times to function in academic contexts. For example, children with specific learning disabilities (Mathematical Learning Disabilities (MLD) and Reading Learning Disabilities (RLD)) might experience more problems during remote learning than their TD peers, due to the planning, working memory and executive functions deficits inherent to their disorder (De Weerdt et al., 2013). In the current study we aim to expand our knowledge of remote learning during the COVID-19 pandemic (e.g., Becker et al., 2020; Dong et al., 2020) by investigating the potentially different impact of the remote learning period on children with and without DD. We focus on several outcome variables related to their learning experiences rather than on learning performance. In addition, we integrate the research variables into an established theoretical model to build and test a holistic perspective. This leads to an understanding of educational quality and learners' educational experiences that moves beyond fragmentized knowledge and might help educational provisions or be helpful to scaffold potential future (forced) periods of remote learning.

The model applied in the current study is the Opportunity-Propensity (O-P) Model (Byrnes, 2020; Byrnes \& Miller, 2007; Wang et al., 2013) that integrates variables and processes associated with predictors of learning, and especially helps gaining insight into how predictors are interrelated, and whether some are more important than others. More specifically, according to the O-P model, learning outcomes depend on three categories of predictor factors: 1. Distal factors, 2. Opportunity factors and 3. Propensity factors. All processes and variables that define the exposure to learning processes and content (e.g., teachers' instruction and parental involvement in schooling) are considered opportunity factors. Propensity factors can be defined as the variables that make children willing (e.g., motivation) and/or able (e.g., prior knowledge and intelligence) to take advantage of opportunities. Distal factors are present already relatively early in a child's life and have a direct effect on learning. They help explaining why some children are exposed to richer opportunity contexts and/or can build on stronger/weaker propensities for learning than others (e.g., SES and gender).

It is important to consider this model as a recursive model, in which outcome variables at one point in time (e.g. learning achievement), become propensity variables (e.g. prior knowledge) at the next point in time (Byrnes, 2020). Studies applying this model (e.g. Baten \& Desoete, 2018; Byrnes \& Miller-Cotto, 2016; Lewis \& Farkas, 2017) have found that propensity factors are the strongest predictors for learning outcomes, after controlling for distal- and opportunity factors. In addition, within each factor cluster, some variables and processes seem to be more important than others (Byrnes, 2020). Prior knowledge and intelligence for example (propensity factors) have been found to be stronger predictors for academic outcomes than SES (distal factor) when they are examined together in a model (Marks, 2016, 2017). In addition, children who were more able and willing to learn, took more advantage of the given opportunities, suggesting that opportunity factors may work through propensities instead of having solely an immediate effect on learning outcomes (Byrnes, 2020).

\section{Opportunity-Propensity Predictors for (Online) Learning (During COVID-19)}

\section{Distal Factors}

An established distal variable with a long history in educational effectiveness research, is SES. Although SES was initially considered as a key predictor associated with educational outcomes, the effect was found to be halved when taking into account genetic effects (Marks, 2017; Peterson $\&$ Pennington, 2015). In addition, after controlling for intelligence or prior achievement, rather weak relationships were found between SES and educational outcomes (Marks, 2017; Rodríguez-Hernández et al., 2020). It seems that SES plays a more important role when children are younger, after which its impact declines once children gain more educational and learning experiences, usually around nine years old (D'Angiulli et al., 2004; da Rosa Piccolo et al., 2016). Anyway, previous studies revealed that children from families with low SES are more strongly affected by COVID-19 related school closures than peers from families with high SES (Engzell et al., 2021; Gore et al., 2021; Maldonado \& De Witte, 2021).

Further, there are parental characteristics that can be considered distal factors in influencing children's educational outcomes. When parents have a DD for example, this potentially influences how they handle their children's learning process. In addition, DD are highly heritable. Children of parents with a DD reflect an elevated likelihood to meet the criteria of that same or another DD, or at least experience 
subclinical features (Barry et al., 2007; Olson, 2011; Snowling \& Melby-Lervåg, 2016; Thapar et al., 2013; Tick et al., 2016; Willcutt et al., 2010). DD in parents may have a significant impact on the richness or nature of the home environment. In families with a parent with Attention Deficit Hyperactivity Disorder (ADHD) symptoms, for instance, there is likely to be more chaos, less monitoring of childbehaviour and higher inconsistency in parental behaviour (Friedrich et al., 2017; Johnston et al., 2012), which in turn is associated with lower academic performance in children (Ackerman \& Brown, 2010). Parents with Autism Spectrum Disorder (ASD) furthermore experience more difficulties in supporting their children with problems they also experience themselves, such as social and communication difficulties. However, they might be more motivated to adhere to interventions focusing on these problems (Karst \& van Hecke, 2012) and some parents who share the ASD diagnosis with their children also indicate to better understand and meet their children's needs (Dugdale et al., 2021).

In the context of the current study, distal factors that might interrelate with parental and child experiences were pressurized due to the COVID-19 lockdown. For example, some parents lost their job and subsequently their monthly income, other parents worked from home and were (not) able to help their children with schoolwork, while still other parents were health-care professionals, working more hours away from home than usual. Furthermore, higher educated parents were probably more able to telework than lower educated parents.

\section{Opportunity Factors}

Previous research indicates that children perform better at school if their parents are involved in their education at home (Desforges \& Abouchaar, 2003; Harris \& Goodall, 2008; Hattie, 2008). Parental involvement positively predicted children's engagement in schoolwork and academic achievement, and was associated with lower drop-out rates (Park \& Holloway, 2013). Research explains this by pointing out how higher parental involvement is related to higher parental aspirations (Duppong Hurley et al., 2017). It is therefore not a surprise that, in children between 7 and 16 years old, parental involvement was even found to be of greater importance for cognitive development than parental education, family background and family size (Feinstein et al., 1999). Three factors help explaining the influence of parental involvement in their children's education: (1) the extent to which parents believe that their involvement is expected from the school (2) the amount of responsibility parents feel for being involved combined with their own estimates of their capacities to do so and (3) their available time and energy for being involved (e.g., Hoover-Dempsey \& Sandler, 1997; Maríñez-Lora \& Quintana, 2009; Park \& Holloway,
2013). Going back to SES, research shows that parents of lower income families are less involved in their children's education (Lee \& Bowen, 2006), and that when encountering more difficult learning content, parents feel less capable to assist their children's homework (Hill \& Tyson, 2009). Next to parental involvement, opportunities to learn at home also arise from the school itself. In a survey-study, parents indicated that different teachers within one school did not always align the tasks and homework they give to students with each other, which was frustrating for both parents and children (Baumgartner et al., 1993). In addition, research revealed that homework was not always adapted to children's individual characteristics or special educational needs (for example for children with DD; Bryan \& Burstein, 2004) and that students were not always provided with informative feedback after handing in their assignments (Bryan \& Burstein, 2004; Salend \& Schliff, 1989; Xu, 2011), even though these practices improve the homework completion rates (Bryan \& Burstein, 2004). Especially in secondary education, homework completion has been significantly related to better academic performance (Hattie, 2008).

In the context of home learning due to the pandemic, more parental involvement was required than during regular school-times. However, potentially not all parents felt the same expectations of schools and teachers regarding their involvement, and some parents might have felt more capable than others to support their children's learning. In addition, not all parents had enough time to help their children with their schooling (for example due to working from home, being a health-care professional, care for other children, etc.). At the school-level, there were likely differences between schools in how they organised online learning (e.g., learning methods, feedback on tasks) and in the way teachers communicated with students, other teachers and parents. This could have been influenced by school level, since secondary schools are differently organised than primary schools.

\section{Propensity Factors}

As stated above, these factors include variables related to children willing (e.g., motivation) and/or being able to carry out tasks. When it comes to the latter, intelligence is one of the most investigated individual characteristic in relation to academic achievement. Fluid intelligence was moderately related to reading and mathematics. This is especially the case for more complex skills such as word number problems, as compared to more basic skills, such as addition with numbers below 100 (Peng et al., 2019). But, besides intelligence, other cognitive and non-cognitive propensity variables have been addressed in the literature. Studies underpin the importance of cold (working memory, planning, extent to engage in rehearsal, taking 
initiative...) and warm executive functions (e.g., emotion regulation, inhibition control; Mercader et al., 2018). In the context of COVID-19 it was for example shown in several studies that worries about getting infected with the disease (self or relative) are related to more negative affect and feelings of anxiety and depression (e.g., Giusti et al., 2021; Saravanan et al., 2020), especially in girls (e.g., Elmer et al., 2020; Rajkumar, 2020; Rodríguez-Hidalgo et al., 2020) and that these feelings in turn are negatively related to academic motivation and performance (Cao et al., 2020; Giusti et al., 2021).

Another cluster of propensity variables is related to motivation, volition, and level of engagement (Martin \& Lazendic, 2018). This affects, for example, the time children spend on homework and has shown to be a significant predictor of grades and achievement (Cooper et al., 2006). According to the Self-Determination Theory (SDT; Ryan $\&$ Deci, 2017) the underlying reasons of children's school behaviour can be divided into more autonomous forms of motivation (e.g. working for school out of interest and curiosity and fully endorsing the personal significance of homework) and more controlled forms of motivation (e.g. working for school because of feeling pressured to meet external demands or to avoid internal pressures such as guilt or shame; Ryan \& Deci, 2000). Autonomous, relative to controlled motivation, is associated with better academic performance (Baten \& Desoete, 2018; De Naeghel et al., 2012; Vansteenkiste et al., 2006). Alfaro et al. (2009) even suggested that child motivation could compensate for risk factors such as low intelligence when predicting academic achievement. In the context of reading for example, it was found that autonomous motivation contributed more to the reading ability of low performers than to the reading ability of high performers (Logan \& Medford, 2011), and Chen et al., (2018) found that motivation reduced the negative effect of low SES on reading ability. Further, autonomous motivation in the academic context was found to be higher in girls compared to boys (Brouse et al., 2010; Ryan \& Deci, 2000) and to decline when students became older (De Naeghel et al., 2016; Gnambs \& Hanfstingl, 2016). In the context of the pandemic, school closures were found to be associated with a decrease in academic motivation (Smith et al., 2021; Zaccoletti et al., 2020). Autonomous motivation was not only shown to predict achievement, but also learning experiences. Baten et al. (2020) for example, observed in an experimental study in the fourth grade that children with more autonomous motivation felt less irritated while solving a math task and found math exercises more interesting than children scoring high on controlled motivation, independent of other factors such as task difficulty.

The importance of propensity factors stresses the need to look at child diagnosis to map the factors that help explaining individual differences in children's capacity and willingness to take advantage of learning opportunities (Byrnes, 2020), in regular as well as in COVID-times.

Children with DD seem to experience more academic problems than TD children do (Desoete \& Warreyn, 2020; Dowker, 2020; Pieters et al., 2012), also in the pandemicrelated remote learning context (Aishworiya \& Kang, 2021). In general these children do not only have more problems with self-regulation compared to children without DD (Berkeley \& Larsen, 2018; Doyle, 2006; Jokić \& Whitebread, 2010; Montague, 2008; Ozonoff et al., 2007; St Clair et al., 2019), they also receive extra support in regular school times, which was often discontinued during the pandemic (Kong, 2021; Murphy et al., 2021). It was for example shown that specific help for students with ADHD in the United States was only continued for $59 \%$ of the students during the closure of the schools in May/June 2020 (Becker et al., 2020). This is in contrast with the fact that during regular school holidays, therapy is often continued because of the importance of its intensity and consistency. Sometimes traditional support was replaced by tele-therapy, therapy delivered through technology like video conferencing, although this could not replace real-life support (Aishworiya \& Kang, 2021; White et al., 2021). Children with DD also may have had more difficulties than their TD peers to understand the rationale for the environmental changes following the COVID-19 outbreak (Aishworiya \& Kang, 2021). It has been observed that the loss of daily routine and structure is disadvantageous for children with DD in general (Mulligan, 2001), especially for children with ASD (Latzer et al., 2021; White et al., 2021). It has been recommended that, in order to improve the effectiveness of online learning (not necessarily in a pandemic context), the characteristics of the DD, such as less developed communication skills, a shorter attention span, or difficulties adapting to change, should be taken into account (Ingersoll \& Berger, 2015), for example by implementing daily routines, using visual support for the learning content and to carry on with (real-life) therapy as much as possible (Aishworiya \& Kang, 2021).

Academic problems are easily observed in children with learning disabilities (MLD or RLD), since the difficulties with learning are explicitly part of the criteria and characteristics of the disorder (American Psychiatric Association, 2013). During the COVID-19 lockdown, children with RLD (compared to TD children) demonstrated more conduct problems (Soriano-Ferrer et al., 2021), more emotional problems (anxiety and feelings of depression; Forteza-Forteza et al., 2021) and more problems with hyperactivity and inattention (Soriano-Ferrer et al., 2021). In addition, these children reported more difficulties with following online classes than their TD peers (Baschenis et al., 2021; Zawadka et al., 2021). Furthermore, the reading skills of about $60 \%$ of children with RLD in an Italian study improved less than expected during the school-closures. On the other hand, children 
with RLD in the same study reported less worries about the school-closures than their TD peers, possibly because the school context usually triggers feelings of inadequacy in these children (Baschenis et al., 2021).

ADHD also seems to have a substantial impact on academic outcomes. About $80 \%$ of children with ADHD were reported to underperform at school (DuPaul \& Stoner, 2003; Loe \& Feldman, 2007). They obtained lower grades for reading and mathematics (Loe \& Feldman, 2007; Rodriguez et al., 2007) and had a higher risk for grade retention (Loe \& Feldman, 2007) than their TD peers. Especially symptoms of inattention (rather than hyperactivity or impulsivity) were related to lower academic outcomes (Barry et al., 2002; Loe \& Feldman, 2007; Rodriguez et al., 2007; Thorell, 2007). Within the pandemic context, students with ADHD showed more conduct- (Nonweiler et al., 2020) and learning problems than their neurotypical peers, while their parents experienced more difficulties in communicating with school and in supporting their children with schoolwork (Becker et al., 2020) compared to parents of children without ADHD.

A higher incidence of difficulties with academic skills such as reading comprehension and mathematics has also been reported in children with other developmental disabilities such as ASD and Developmental Coordination Disorder (DCD; Blank et al., 2019; Huemer \& Mann, 2010; Pieters et al., 2012; Titeca et al., 2015). Problems with executive functions such as working memory difficulties (e.g. Baten \& Desoete, 2018; Grigorenko et al., 2019), slower processing speed (Theiling \& Petermann, 2016), cognitive flexibility issues (Korzekwa, 2012), shorter attention span for academic tasks (Imeraj et al., 2013) and problems with planning and time management (Sibley et al., 2014) seem to interfere with academic performance (Barry et al., 2002; Daley \& Birchwood, 2010; Diamantopoulou et al., 2007). Moreover, these problems seem to become larger as children grow older because of increasing task difficulty and expectations to solve tasks independently (Bryan \& Burstein, 2004; Cooper $\&$ Valentine, 2001). Specific research within the pandemic context showed less prosocial behaviour (Nonweiler et al., 2020), more problem behaviour and more difficulties in daily life for children with ASD (Colizzi et al., 2020), accompanied with more difficulties with emotion regulation (White et al., 2021). Problems were less pronounced if there was a better support network for the parents (Latzer et al., 2021).

The DD of a child does not only impact the child's academic performance and related behaviour but additionally affects parents. It was found that children with DD place a greater pressure and depend more on the skills of their parents compared to TD children (Harpin, 2005; Rutgers et al., 2007). These children's education can thus be expected to be challenging and difficult, especially if their parents also have a DD. Parental involvement in the schooling of the children for example was shown to be more difficult for parents with learning disabilities (Maguire et al., 2009; Tarleton et al., 2005), ASD (Morris, 2003) and ADHD (Sonuga-Barke et al., 2002). Survey studies in parents indicated more worries and mood-changes for parents (Asbury et al., 2021), more emotional problems for children (Nonweiler et al., 2020) and increased levels of parental stress (Bentenuto et al., 2021; Chan \& Fung, 2021; Soriano-Ferrer et al., 2021) during the COVID pandemic, both for parents of children with and without DD compared to regular times, with higher baseline and follow-up levels of parental stress in the DD group. The increase of parental stress during lockdown for children with DD was associated with the decrease in therapy (Bentenuto et al., 2021).

The pandemic-related changes did not only have an impact on learning-related outcomes, but also on the academic performance itself. A Flemish study pointed out that the school-closures in the context of the COVID-19 pandemic resulted in learning losses for the children of the 2020 cohort compared to the previous cohort, with larger learning losses for more disadvantaged students (Maldonado \& De Witte, 2021). Furthermore, a systematic review on the effect of COVID-19 related school closures showed negative effects on student achievement, especially for younger students and students from lower SES families (Hammerstein et al., 2021).

\section{The Present Study}

From the Opportunity-Propensity point of view, the pandemic situation influenced the balance and position of opportunity factors at the school and the home level. More specifically, the classroom, the teacher(s), the teaching methods used, the social interaction with peers, etc., were mainly replaced by factors in the home environment, such as independent self-regulated learning, remote teaching and less social interaction, potentially negatively impacting students' and parents' experiences. As mentioned earlier, the interaction between certain distal and propensity factors may have changed. Parents may have become unemployed, thereby losing their income, and parents taking up on the teacher role during the remote learning period might have influenced children's motivation to engage in schoolwork. In the current study we examined several distal, opportunity and propensity factors to predict four general outcome variables: children's learning time, perceived effectivity of teacher-driven teaching methods, perceived effectivity of assignment-driven teaching methods and parental satisfaction with the COVID-19 measures taken by the school. The operationalization of the O-P model for the current study is displayed in Fig. 1. We compared the experiences of children with and without DD and of children in primary with children in secondary education. 


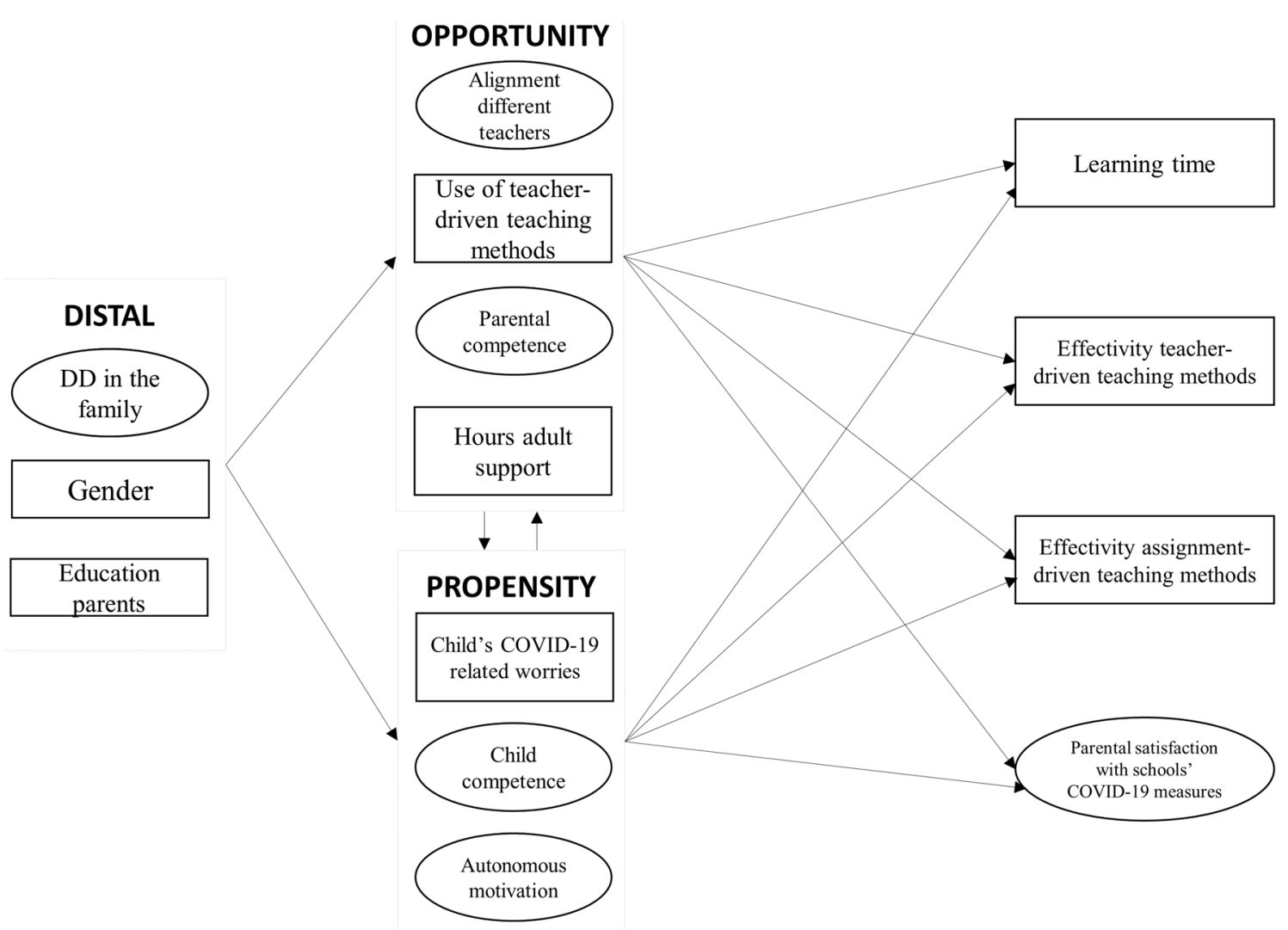

Fig. 1 Concrete Operationalization of the Opportunity-Propensity Model in the Current Study. For Specific Hypotheses, See the End of the Introduction Section. $\mathrm{DD}=$ Developmental Disorders

Two research questions were addressed:

(1) Are there significant differences in learning experiences (i.e., the outcome variables) between children with and without DD and between children in primary compared to secondary education?

\section{Learning Time}

As a result of the remote learning situation, children were required to work more independently for school. We can expect that this resulted in an increase of learning time at home, compared to regular school times, although this probably largely depended on the available opportunity and propensity variables (see Research Question 2). However, independent of specific school and home situations (opportunity factors) and child characteristics (propensity factors), we expected a higher increase in learning time for children with DD than for TD children. This is based on the difficulties children with DD have with self-regulation (e.g., Berkeley \& Larsen, 2018; Doyle, 2006; Jokić \& Whitebread, 2010; Montague, 2008; Ozonoff et al., 2007; St Clair et al., 2019), attention, planning, working memory and executive functioning (De Weerdt et al., 2013), which makes it more difficult for them to independently process learning materials. However, it is also possible that because of these difficulties, DD children will have given up easier, resulting in a smaller increase in learning time for them compared to TD children. In addition, it can be expected that the difficulties of children with DD will have interfered more in secondary school, because of an in increased task difficulty (Bryan \& Burstein, 2004; Cooper \& Valentine, 2001).

Independent of child diagnosis, a higher increase in learning time for primary than secondary school children can be expected because these children are less used to receive homework and to work individually for school after school hours than the older children. As such, they will probably have lost more time getting used to individually process their learning materials than secondary school children who are already more familiar with assignment-driven teaching methods.

\section{Effectivity Teaching Methods}

On average, we expected that the teaching methods used during remote learning would be less effective for children with DD than for their TD peers. It can be assumed that 
the sudden switch to remote learning was challenging for teachers, resulting in the use of learning materials that are less adapted to the individual needs of children with DD. Especially for assignment-driven methods, children are more dependent on oneself than with teacher-driven teaching methods such as live online video lessons, in which the teacher can interact with the student and adapt learning content, tempo, etc. to his/her observations of what the different children in their class are struggling with (just as in the regular classroom practice). The expectation that the teaching methods will have been less effective for DD children is reinforced by the already reported extra difficulties children with DD have with learning, both in regular school times (Nonweiler et al., 2020) as during the school-closures (Baschenis et al., 2021; Soriano-Ferrer et al., 2021; Zawadka et al., 2021).

With regards to school level, assignment-driven teaching methods might have been more effective for secondary school students, who are already more familiar with teaching methods in which they are encouraged to work more individually, resulting in the average effectivity of both teaching methods expected to be higher for them. However, a lower perceived effectivity for older children is also a possibility because of the more difficult learning content in secondary school.

\section{Parental Satisfaction with Schools' COVID-19 Measures}

We expected parents of DD children to be less satisfied than parents of TD children, because schools suddenly had to find new ways to communicate with their students with less time for the teachers to adapt the learning content to the several difficulties of children with DD in their classroom. Similarly, we expected parents of secondary school children to be less satisfied with the schools' measures because the more difficult the learning content gets, the more important parents will find a clear and structured communication so the more critical they will be when evaluating how the school handles the situation.

The abovementioned hypotheses about the role of child diagnosis concern differences between a group of children with DD and a group of TD children. The available research hardly presents a consistent base to put forward-in the context of the present study - sub-hypotheses that differentiate between different DD's. This would be possible in future research when catering for a more fitting sampling approach to address this point of interest. Nevertheless, as an extra analysis we will explore potential differences in effects related to the different DD, as a base for this future research (See Appendix Part 4).
(2) Which distal, opportunity and propensity factors predict children's learning time, perceived effectivity of teacher-driven teaching methods, perceived effectivity of assignment-driven teaching methods and parental satisfaction with the COVID-19 measures taken by the school? Is the predictive value the same for children with/without DD and for primary/secondary school children?

\section{Distal Factors}

Direct Effects For the distal factors, we expected a direct effect of parental education on parental satisfaction with the COVID-19 measures of the school, with higher educated parents being more satisfied because these parents might have found it easier (e.g., Hoover-Dempsey \& Sandler, 1997; Maríñez-Lora \& Quintana, 2009; Park \& Holloway, 2013) to understand instructions from school and help their children with schoolwork, therefore getting less easily frustrated about how the school handles the remote teaching situation.

Indirect Effects In addition, we expected parental education and disorders in the family to impact the outcomes through opportunity factors, with higher educated parents perceiving themselves as more competent and investing more hours supporting their children, and parents with DD perceiving themselves as less competent. These same two variables were also thought to influence the outcomes through propensity factors, with parental education and disorders in the family predicting child competence to a certain extent. When it comes to a child's gender, we also expected indirect effects through propensity factors with the prediction of girls being more autonomously motivated (Brouse et al., 2010; Ryan \& Deci, 2000) and having more COVID19 related worries (propensities) than boys (Elmer et al., 2020; Rajkumar, 2020; Rodríguez-Hidalgo et al., 2020).

\section{Opportunity Factors}

Based on previous studies that applied the O-P Model (e.g., Byrnes, 2020) the propensity variables were expected to be the most predictive. However, the remote learning situation differs the most from the regular school situation in terms of the opportunity factors. In comparison with earlier O-P studies, the results of the present COVID-study might therefore show that opportunity factors played a larger role. Earlier research suggests to look in this context at a stronger alignment between teachers (Baumgartner et al., 1993), larger use of teacher-driven methods, a stronger feeling of competency in parents and more hours of adult support (e.g., HooverDempsey \& Sandler, 1997; Maríñez-Lora \& Quintana, 2009; Park \& Holloway, 2013). For these factors, we predicted 
both direct effects on outcome variables as effects mediated through propensity factors.

Direct Effects More alignment between different teachers would reflect more clarity for the children and was thereby expected to reduce their learning time and to improve the effectivity of the teaching methods. In addition, parents might have observed less difficulties in their children when there was more alignment between different teachers, resulting in a higher satisfaction about the schools COVID-19 measures. Further, the use of teacherdriven teaching methods was expected to increase children's learning time but also to improve the effectivity of assignment-driven teaching methods because teacherdriven methods are more similar to the traditional classroom teaching approach, than only using a task and assignment-driven approach. How effective an assignment was for a child was probably enhanced by the teacher explaining the learning content before instructing the assignment. Especially if teachers also gave live online feedback (e.g. in online video lessons), we expected the assignments to reach their goals more effectively (Bryan \& Burstein, 2004; Hattie, 2008; Salend \& Schliff, 1989; Xu, 2011). Similarly, we expected parents to be more satisfied when the school used teacher-driven methods because of the similarities with the traditional learning context. Further, we expected parents who reported to have spent more hours supporting their children with schoolwork to notice an increase in learning time for their child during remote learning compared to before. In addition, we expected that both teaching methods will have been evaluated as less effective and that parents will have been less satisfied with how the school handles the COVID-19 situation if they found themselves spending a lot of time in the support of their child with schoolwork. Their more negative evaluation would then be a reflection of themselves having to solve the difficulties and inconsistencies the child is struggling with because of the (in the opinion of the parents) poor approach of the school. Parents who rated themselves as being more competent were expected to be more satisfied with the schools' measures because these parents would - probably unconsciously-more easily cope with difficulties or inconsistencies in the schools' approach resulting in less criticism.

Indirect Effects For the indirect effects through propensity factors, we hypothesized that parents who perceived themselves as more competent will also have rated their children as more competent. We also expected that the parental perception about how much alignment there was between different teachers and how many hours they found themselves spending on supporting their child with schoolwork would influence the parental perception about the autonomous motivation of the child. It can be argued that more autonomously motivated children will have solved inconsistencies between different teachers themselves, asking less help from their parents, resulting in parents not knowing about a low alignment rate between teachers.

\section{Propensity Factors}

Also for the propensity predictors, direct effects as well as effects through opportunity factors were expected.

Direct Effects For the direct effects, a lower increase in learning time was expected to be reported by parents who estimated their children as competent and more autonomously motivated to work for school. More specifically, we did not expect that these children will have worked more during remote learning than during regular school times. However, for the children with less capacities and less motivation to work for school, parents will probably have seen the difference with regular school times more easily, and therefore might have reported a higher increase in learning time. In addition, parents who find their children more competent and more motivated will probably have rated the teaching methods as more effective and might have been more satisfied about how the school handled the remote teaching situation, because these children will have relied less on their parents help. Further, the effectivity of both teaching methods was expected to be reduced if a child reflected more COVID-19 related worries (Cao et al., 2020; Giusti et al., 2021).

Indirect Effects For the indirect effects, parents perceiving their child as more competent might have rated teachers as being more aligned and parents perceiving their child as more competent and/or more autonomously motivated might have estimated that they spent less time supporting their child with schoolwork.

\section{Comparing Children With/Without Developmental Disorders and Primary/Secondary School Children}

Lastly, in an explorative way, we examined whether the predictive value of the distal, opportunity, and propensity factors was similar for children with/without DD and for primary/secondary school children. It is possible that focusing on certain predictors (opportunity or propensity factors) to improve academic performance or related learning experiences might be less effective for children diagnosed with DD, compared to TD children. The same applies to the more demanding learning content in secondary school (Hill \& Tyson, 2009), possibly influencing the strength of the predictors for the outcome variables. 


\section{Methods}

\section{Participants}

Participants were 2222 parents of children with $(n=779$, $35.10 \%$ ) and without ( $n=1443,64.90 \%$ ) DD between 5 and 19 years old, who filled out a survey on the impact of school strategies and the home environment on learning experiences during the COVID-19 pandemic. In total, 3506 parents started to fill out the survey, however after data pre-processing, the final sample size consisted of 2222 parents. Among them, 1949 (87.70\%) finished a complete questionnaire. Implausible values in the dataset were deleted or replaced. More details about the pre-processing of the data can be found in Appendix Part 1.

The survey was mostly filled out by mothers $(n=2087$, $93.90 \%$ ) and the majority of the respondents and their partners spoke Dutch with their child (respectively $97.70 \%$ and $95.50 \%)$. All Flemish provinces were represented. Of the participants, 1894 (85.20\%) were married or lived together with a partner, and 1689 (76.30\%) of the participants and $1066(56.60 \%)$ of their partners had at least a Bachelor's degree. Respondents and their partners were on average $41.09(S D=5.54)$ years old. Before the COVID-19 measures they worked on average $0.63(S D=1.28)$ days per week from home, while during the time window of the survey administration this was on average $2.63(S D=2.30)$ days per week. Most participating families included two children (56.20\%) and $95.4 \%$ of parents had one (19.5\%), two (57.6\%) or three (18.3\%) children still going to school. Of all respondents and their partners, $3.90 \%$ had RLD, 2.15\% ADHD, 1.40\% ASD, 0.90\% MLD, 0.25\% Developmental Language Disorder (DLD) and $0.20 \%$ DCD.

The children of concern in this study were on average $10.19(S D=3.15)$ years old (range $=5-19)$ and 1220 (54.90\%) of them were boys. Most children attended regular education $(n=2133,96 \%) .1574(70.84 \%)$ of the children attended primary school and $92 \%(n=2044)$ of the children were staying fulltime with the respondent during the home learning period. Of the children with DD, 306 (39.28\%) reflected comorbidity. See Table 1 for demographical details of the children.

More demographical details regarding all different DD's and analysis results of the comparisons between DD and TD children and between children with one versus multiple diagnoses for age, gender, school level and school type can be found in Appendix Part 2.
Table 1 Demographical Data of the Children of Concern in the Present Study

\begin{tabular}{ll}
\hline & $M(S D)$ or $n(\%)$ \\
\hline Age & $10.19(3.15)$ \\
Gender & \\
Boy & $1220(54.90 \%)$ \\
Girl & $1001(45.00 \%)$ \\
Type of education & \\
Regular education & $2133(96.00 \%)$ \\
Special education & $89(4.00 \%)$ \\
School level & \\
Primary & $1574(70.84 \%)$ \\
Secondary & $648(29.16 \%)$ \\
Diagnosis & \\
Typically developing & $1443(64.90 \%)$ \\
Developmental disorder & $779(35.10 \%)$ \\
No comorbidity & $473(60.70 \%)$ \\
Comorbidity (>1 developmental disorder) & $306(39.30 \%)$ \\
\hline
\end{tabular}

More details on the specific developmental disorders represented in the current sample can be found in Table 4

\section{Procedure}

The survey concerned the period of March $16^{\text {th }}$ until April $6^{\text {th }} 2020$ (the start of the Easter holidays), the first period for which the Flemish government decided to close all schools in the context of the pandemic. Parents with at least one school-aged child (primary or secondary education) could retrospectively fill out the questionnaire through LimeSurvey, a free and secure open-source online survey application, between April $3^{\text {rd }}$ and April $17^{\text {th }}$ 2020. Participants were recruited by using convenience sampling through social media (both general pages and pages or groups related to specific DD), clinical psychologists, speech and language therapists and other professionals in the network of the researchers. It is possible that some parents forwarded the invitation to others who fitted the inclusion criteria (snowball sampling). Informed consent was obtained through an information letter and an informed consent form, and at no point during the survey identifiers of participants were collected (e.g. name, date of birth, IP-address). Filling out the questionnaire took approximately $20 \mathrm{~min}$ and participation could be withdrawn at any time without needing to provide an explanation and without consequences. In addition to the questions of the survey, every page of the questionnaire referred to (online) resources related to the coronavirus or to mental health support, some of them specifically related to DD. At the end of the survey, parents were asked, without any obligation, whether we could contact them again for future participation in follow-up studies on this topic. Lastly, participants could send an e-mail to the researchers 
to obtain a short summary of the results of the study (on a group level).

This study was preregistered in the Open Science Framework Repository (OSF; https://osf.io/z2wuv) and was approved by the Ethical Committee of the Faculty of Psychology and Educational Sciences of Ghent University (EC/2020/45).

\section{Survey}

The questions of the survey were mostly researcher-developed, based on literature and theoretical models about learning and developmental disorders. The first and second part of the survey focused on family and child demographics. In the next part, parents were asked about COVID-19 measures taken by their child's school and their satisfaction about these measures. The fourth part centered on child motivation and well-being. The final part examined parental wellbeing. At the end of the survey parents could add information through an open-ended question; results not discussed in the current paper.

In the following parts of this method section, the variables of concern to answer the research questions will be organized according to the O-P model. If several variables were combined into a latent variable, the fit of the construct will be discussed further in this paper.

\section{Distal Factors}

Distal factors included in the model were child gender, presence of DD in the family (as a latent variable, combining the presence of a DD in parents and/or siblings) and parents' educational level (ranging from 1 for not finishing primary school to 7 for Master's degree or $\mathrm{PhD}$ ). An average parent score was calculated for both parents, if applicable.

\section{Opportunity Factors}

Alignment Between Different Teachers If children received information about schoolwork from different teachers, parents were asked to rate on a 10-point scale how much these different teachers aligned with each other on 5 topics (i.e., assignments followed the same structure, information of different subjects was communicated together, the same communication channel was used, the same software was used, the different subject deadlines were aligned). The information for these topics was collapsed into one latent variable.

Use of Teacher-Driven Teaching Methods A list of teaching methods was presented to the parents, after which they could select the method(s) that was/were used in the online schooling of their child(ren). Some of these methods were teacher-driven (i.e. pre-recorded lessons, online live group sessions, chatboxes, teaching by telephone), whereas the other methods were classified as assignment-driven (i.e. short term assignments, long term assignments, voluntary assignments). Since only $3.78 \%$ of teachers $(n=84)$ did not use assignment-driven methods, only the extent of use of teacher-driven methods was included in the analysis model ( $0=$ the school did not use these methods; $1=$ these methods were used by the school).

Parental Competence Parents indicated with a 10-point scale how competent they felt helping their children with math, reading, spelling, and other courses. This information was collapsed into one latent variable.

Hours of Adult Support Parents were asked how many hours per week they and their partner were involved in helping their child with schoolwork. The sum score of both parents' time investment was used in the model.

\section{Propensity Factors}

Competence Parents were requested to estimate the competence of their child between September and February of the ongoing school year ( $=$ the period before the home learning period of concern in the current study) in comparison with other children, for different subjects (mathematics, reading, spelling and other subjects) on a 10-point scale. This information was combined into one latent variable.

Autonomous Motivation Children's motivation to work for school during the home learning period was measured using an adapted measure of the Academic Self-Regulation Questionnaire (Ryan \& Connell, 1989), which was successfully used in earlier studies (e.g., Soenens et al., 2012). Parents were asked to indicate on a 5-point scale how important (completely not important to very important) each of the listed motives was for their child to work for school during the home learning period (e.g., "My child was motivated to work for school during the home learning period because ..."). Eight items $(\alpha=.95)$ tapped into autonomous motivation (= with 4 items representing the subscale identified regulation and 4 items representing the subscale intrinsic motivation); e.g., "... because he/she is highly interested in studying/working for school". A latent variable was constructed with the item scores as indicators.

COVID-19 Related Worries Parents answered on a 10-point scale how much their child worried about the social distancing measures and about someone in their environment getting infected with COVID-19. An average score of both items was included in the model.

\section{Outcome Variables}

Learning Time Parents were asked how much time (in hours) their child spend daily on schoolwork, both before and during the home learning period. A difference score was 
calculated with a positive score indicating an increase and a negative score indicating a decrease in daily learning time.

Perceived Effectivity of Teacher-Driven Teaching Methods Parents were asked to estimate how well the teacherdriven methods used by the school during the home learning period, worked for their children on a 5-point scale (not good to very good). An average score of both parents (if applicable) was included in the model.

Perceived Effectivity of Assignment-Driven Teaching Methods For assignment-driven methods used by the school, an average score combining parents' estimation on how well these methods worked for their children was included too.

Satisfaction with Schools' COVID-19 Measures Parents were provided with 7 statements and were asked to indicate how much they agreed with each statement on a 10-point scale (not at all to completely; i.e., "I am satisfied with the communication of the school", "I am satisfied with the provided structure by the school", "I am satisfied with the amount of support the school provides", "I find it easy to know what my child has to do for school", "My child finds it easy to know what to do for school and what the deadlines for tasks are", "I am satisfied with the amount of feedback my child gets on tasks and assignments", "The feedback my child gets is clear and helpful"). A variable was constructed, combining item scores as indicators of the latent construct.

\section{Analysis Approach}

Preliminary analyses included the construction of latent variables based on the item-indicators described in the method section. To confirm the validity of the latent constructs, Confirmatory Factor Analysis (CFA) was used for each of the constructs, using the Lavaan package in R (R Core Team, 2020; Rosseel, 2012). Indicators were first correlated with each other, to avoid adding highly correlated indicators in the same latent construct. When a high correlation $(r \geq .70)$ was observed, the item with the highest standard deviation was retained in the model, unless this would result in the latent construct being based on only two indicators. In the latter case, all items were retained. The indicators were tested for each latent variable with a CFA approach; covariances between errors were allowed, based on modification indices. Model adaptations were only adopted if this was theoretical sound and if this resulted in an improved fit of the original chi-square of at least $20 \%$. Goodness-of-fit was evaluated using established fit measures (cut-off values: .06 for root mean square error of approximation (RMSEA), .08 for standardized root mean square residual (SRMR), .95 for comparative fit index (CFI)) of $\mathrm{Hu}$ and Bentler (1999), in addition with a goodness of fit index (GFI) equal to or higher than .95 and the adjusted goodness of fit index (aGFI) equal to or higher than .90 (Schermelleh-Engel et al., 2003). The full information maximum likelihood (FIML) estimator was used to calculate parameter estimates, in order to deal with missing data. This estimator takes into account all available data and implies values for missing data, based on the observed data (Enders \& Bandalos, 2001).

Further, to investigate if there were significant differences in the outcome variables between children with and without DD and between children in primary compared to secondary education (Research Question 1), a Multivariate Analysis of Covariance (MANCOVA) was performed with a dummy variable (0/1) referring to the absence/presence of DD and primary/secondary education as between-subjects variables and the outcome variables as dependent variables. Gender was included as a covariate in the model because of the unbalanced boy-girl ratio in the DD group compared to the TD group. For the latent variable parental satisfaction with schools' COVID-19 measures, a linear combination score was calculated to include this variable in the MANCOVA. More specifically, a sum score was created for the five items, using the parameter estimates retrieved from the CFA, multiplicated with the item score. To grasp the effectivity of the teaching methods, an average effectivity score for the teacher-driven and assignment-driven methods was used. Using both variables separately as outcome variables in the MANCOVA reduced sample size for the MANCOVA (from $n=1981$ to $n=537$ ). This was the case because the effectivity of teacher-driven methods only had to be rated by parents when they indicated that the school used these methods (i.e. in only 574 of cases or $25.83 \%$ of the sample). The MANCOVA was therefore conducted considering three instead of four outcome variables. In an exploratory way, an extra MANCOVA analysis was performed in which the dummy variable for the absence/presence of a DD (0/1) was replaced by a dummy variable for the absence/presence of each of the different disorders (0/1) as between-subject variables.

Next, to investigate which distal, opportunity, and propensity factors predicted the outcome variables (Research Question 2), a Structural Equation Model (SEM) was tested with the Lavaan package of R (R Core Team, 2020; Rosseel, 2012). Several regressions were tested in the model, based on specific hypotheses as described at the end of the introduction section. Both parental opportunity factors (parental competence and hours of adult support) were allowed to covariate, as were child competence and autonomous motivation. Some variables in the model were observed variables, whereas others were included as latent constructs taking into account the preliminary CFA's. Model adaptations for the structural model were only allowed if the same rules as in the CFA's were fulfilled and goodness-of-fit was also evaluated in the same manner as in the CFA's. Regression parameters for the structural model were estimated using 
bootstrapping (1000 iterations) and the FIML estimator (Enders \& Bandalos, 2001).

Finally, to examine if the predictive value of the predictors differed when taking into account the presence of DD and school level, multi-group SEM was applied in the Lavaan package of R (R Core Team, 2020; Rosseel, 2012). To justify group comparisons for the structural part of the SEM, metric measurement invariance was examined. When there were no significant differences between a model with and without equality constraints (i.e., the factor loadings for the CFA's constrained to be equal or allowed to be freely estimated across groups), this proved that the latent factors had the same meaning in both groups. Subsequently, regression paths could be compared between groups by similarly comparing two models with and without equality constraints for the regression parameters. When significant differences were found, one regression path at a time was constrained to be equal across groups and by means of a chi-square difference test compared with a model without constraints to find out which of the paths specifically differed between groups.

\section{Results}

\section{Preliminary Analyses}

Preliminary analyses consisted of creating latent constructs and confirming their validity through Confirmatory Factor Analysis (CFA). For details on this, see Appendix Part 3.

\section{Primary Analyses}

Research Question 1: Are there significant differences in the outcome variables between children with and without DD and between primary compared to secondary school children?

The results of the MANCOVA revealed that DD (0/1), $F(3,1974)=19.10, p<.001, \eta_{p}^{2}=.03$, school level (primary/secondary), $F(3,1974)=20.38, p<.001, \eta_{p}^{2}=.03$ and the interaction effect DD x school level, $F(3,1974)=3.23$, $p=.022, \eta_{p}^{2}=.01$ were significantly impacting the outcome variables on the multivariate level. These effects emerged while controlling for the multivariate effect of gender, $F(3$, $1974)=5.42, p=.001, \eta_{p}^{2}=.01$. Means and standard deviations, together with the multivariate and follow-up univariate results are reported in Table 2.

On the univariate level, the interaction effect DD $x$ school level impacted only the effectivity of teaching methods. More specifically, teaching methods were rated as less effective when children had a DD (main effect) and this difference was even more pronounced in secondary $\left(M(S D)_{T D}=3.51(0.93), M(S D)_{D D}=2.94(1.06), p<.001, \eta_{p}^{2}\right.$

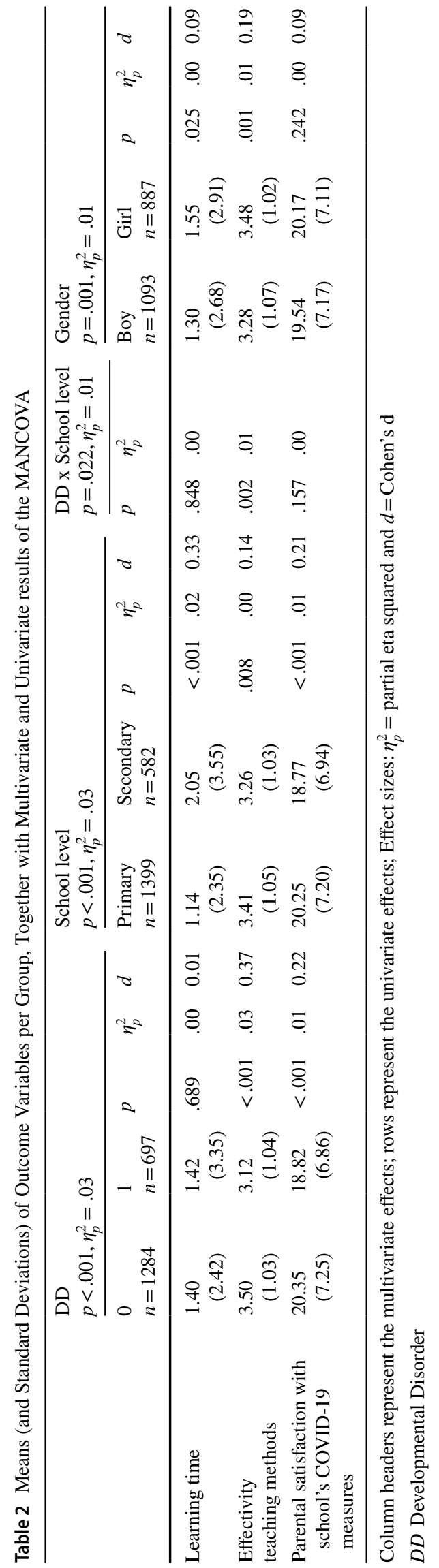


$=.07)$, than in primary education $\left(M(S D)_{T D}=3.49(1.06)\right.$, $M(S D)_{D D}=3.23(1.02), p<.001, \eta_{p}^{2}=.01$; interaction effect). In addition, for the main effects of DD and school level, parents of children with DD were less satisfied with the schools' COVID-19 measures than parents of TD children. Parents of secondary school children reported a higher increase in learning time for their children and were less satisfied with the schools' COVID-19 measures than parents of primary school children. With regards to gender, a higher increase in learning time was reported for girls compared to boys and both teaching methods were rated as more effective for girls than for boys.

In an exploratory way, we examined if there were differences on the outcome variables between children with and without ASD, RLD, ADHD, MLD, DCD and DLD. Results are described in Appendix Part 4.

Research Question 2: Which distal, opportunity and propensity factors predict these outcome variables and is the predictive value the same when taking into account the presence of developmental disorders and school level?

The proposed SEM-model yielded an acceptable fit, $\chi^{2}(363)=1718.80, p<.001 ; \mathrm{CFI}=.92 ; \mathrm{RMSEA}=.04$; $\mathrm{SRMR}=.05, \mathrm{GFI}=.99, \mathrm{aGFI}=.98$. No model adaptations were necessary. The standardized parameter estimates for the structural model, together with $95 \%$ Confidence Intervals can be found in Table 3 .

\section{Prediction of Outcome Variables}

Learning Time As displayed in Fig. 2, the learning time during the home learning period $\left(R^{2}=.08\right)$ was significantly predicted by higher scores for autonomous motivation, the school using teacher-driven methods and the parents reporting to invest more time to support their child with schoolwork. In contrast, when multiple teachers were more strongly aligned, this reduced the learning time during the home learning period.

Effectivity Teaching Methods Parents perceived both teacher-driven methods $\left(R^{2}=.18\right)$ and assignment-driven methods $\left(R^{2}=.29\right)$ as more effective when they rated their children higher on autonomous motivation and when they found multiple teachers to be more aligned with each other. Both teaching methods were furthermore perceived as less effective by parents of children with larger COVID-19 related worries. Specifically for assignment-driven methods, their effectivity was higher when schools also adopted teacher-driven methods and when parents rated their children as more competent. The effectivity was rated lower when parents indicated to invest more time in supporting their children with schoolwork.

Parental Satisfaction with School's COVID-19 Measures Finally, parental satisfaction with the schools' COVID-19 measures was positively predicted by more autonomous motivation in children, by parents finding themselves more competent to support their children with schoolwork, by a stronger alignment between multiple teachers and by the schools' use of teacher-driven methods during the home learning period. Parents reporting to spend more time supporting their children with schoolwork during the home learning period, were less satisfied about the schools' COVID-19 measures.

\section{Prediction of Opportunity Factors}

Parents' perception of the alignment between multiple teachers was positively predicted by parents' perception of child competence. Parental competence was positively predicted by parental education and negatively predicted by DD in the family. No significant predictors were found for the hours of adult support.

\section{Prediction of Propensity Factors}

Autonomous motivation - as rated by parents - was significantly higher in girls compared to boys, and increased when multiple teachers were rated as being more aligned with each other. Children's competence was positively predicted by parental competence and parental educational level and negatively predicted by more DD in the family. Lastly, gender was a significant predictor of the amount of children's COVID-19 related worries, with girls worrying more than boys.

\section{Comparing Children With/Without Developmental Disorders and Primary/Secondary School Children}

For children with and without DD, measurement invariance was established, $\Delta \chi^{2}(16)=21.08, p=.176$, justifying group comparisons for the structural part of the SEM model. Comparing a model with all regression coefficients constrained to be equal across groups with a model without constraints resulted in a significant difference, $\Delta \chi^{2}(36)=52.31, p=.039$, indicating that not all regression paths were the same for DD and TD children. In the TD group, the use of teacher-driven methods led to more parental satisfaction with the schools' COVID-19 measures and to higher perceived effectivity of assignment-driven methods. More hours of adult support were also related to a higher perceived effectivity of assignment-driven methods. In the DD group however, these same predictors seemed to be non-significant. Yet, the effectivity of assignment-driven methods was perceived to be higher for more competent children, in the DD group only. Specific details on the regression parameters can be found in Table 3. When comparing the model for children in primary education with the model for children in secondary education, measurement invariance for the latent factors could not 
Table 3 Standardized Parameter Estimates in the Structural Model, Together with 95\% Confidence Intervals (Bootstrapped - 1000 Iterations) and a Comparison Between Typically Developing Children (TD) and Children with Developmental Disorders (DD)

\begin{tabular}{|c|c|c|c|c|c|c|c|c|c|}
\hline & & \multicolumn{3}{|c|}{ Total Sample } & \multicolumn{5}{|c|}{ TD compared to DD } \\
\hline & & \multirow[b]{2}{*}{$\beta$} & \multirow[b]{2}{*}{$p$} & \multirow[b]{2}{*}{$95 \% \mathrm{CI}$} & \multicolumn{2}{|c|}{$\begin{array}{l}\text { TD } \\
n=1442\end{array}$} & \multicolumn{2}{|c|}{$\begin{array}{l}\text { DD } \\
n=775\end{array}$} & \multirow{2}{*}{$\begin{array}{l}\Delta \chi^{2} \\
p\end{array}$} \\
\hline & & & & & $\beta$ & $p$ & $\beta$ & $p$ & \\
\hline \multirow{3}{*}{ Distal $\rightarrow$ Opportunity } & Education parents $\rightarrow$ Parental competence & .25 & $<.001$ & {$[.20, .30]$} & & & & & \\
\hline & Education parents $\rightarrow$ Hours adult support & .03 & .239 & {$[-.02, .07]$} & & & & & \\
\hline & Disorders family $\rightarrow$ Parental competence & -.16 & .032 & {$[-.30,-.01]$} & -.22 & .009 & -.05 & .499 & .015 \\
\hline \multirow[t]{4}{*}{ Distal $\rightarrow$ Propensity } & Education parents $\rightarrow$ Child competence & .10 & $<.001$ & {$[.05, .15]$} & & & & & \\
\hline & Disorders family $\rightarrow$ Child competence & -.21 & $<.001$ & {$[-.38,-.05]$} & & & & & \\
\hline & Gender child $\rightarrow$ Autonomous motivation & .22 & $<.001$ & {$[.16, .27]$} & & & & & \\
\hline & $\begin{array}{l}\text { Gender child } \rightarrow \text { Child's COVID-19 related } \\
\text { worries }\end{array}$ & .06 & .014 & {$[.01, .10]$} & & & & & \\
\hline \multirow[t]{3}{*}{ Opportunity $\rightarrow$ Propensity } & Parental competence $\rightarrow$ Child competence & .21 & $<.001$ & {$[.14, .27]$} & .19 & $<.001$ & .27 & $<.001$ & .044 \\
\hline & $\begin{array}{l}\text { Alignment different teachers } \rightarrow \text { Autonomous } \\
\text { motivation }\end{array}$ & .10 & .026 & {$[.01, .18]$} & & & & & \\
\hline & $\begin{array}{l}\text { Hours adult support } \rightarrow \text { Autonomous motiva- } \\
\text { tion }\end{array}$ & .09 & .588 & {$[-.23, .40]$} & & & & & \\
\hline \multirow[t]{3}{*}{ Propensity $\rightarrow$ Opportunity } & $\begin{array}{l}\text { Child competence } \rightarrow \text { Alignment different } \\
\text { teachers }\end{array}$ & .16 & $<.001$ & {$[.08, .24]$} & & & & & \\
\hline & Child competence $\rightarrow$ Hours adult support & -.15 & .105 & {$[-.32, .03]$} & & & & & \\
\hline & $\begin{array}{l}\text { Autonomous motivation } \rightarrow \text { Hours adult sup- } \\
\text { port }\end{array}$ & -.13 & .512 & {$[-.50, .25]$} & & & & & \\
\hline Distal $\rightarrow$ Outcome & $\begin{array}{l}\text { Education parents } \rightarrow \text { Parental satisfaction with } \\
\text { schools' COVID-19 measures }\end{array}$ & -.04 & .094 & {$[-.08, .01]$} & & & & & \\
\hline \multirow[t]{12}{*}{ Opportunity $\rightarrow$ Outcome } & Alignment different teachers $\rightarrow$ Learning time & -.12 & $<.001$ & {$[-.17,-.06]$} & & & & & \\
\hline & $\begin{array}{l}\text { Use of teacher-driven methods } \rightarrow \text { Learning } \\
\text { time }\end{array}$ & .09 & $<.001$ & {$[.06, .13]$} & & & & & \\
\hline & Hours adult support $\rightarrow$ Learning time & .22 & $<.001$ & {$[.16, .28]$} & & & & & \\
\hline & $\begin{array}{l}\text { Alignment different teachers } \rightarrow \text { Effectivity } \\
\text { teacher-driven methods }\end{array}$ & .23 & $<.001$ & {$[.13, .32]$} & & & & & \\
\hline & $\begin{array}{l}\text { Hours adult support } \rightarrow \text { Effectivity teacher- } \\
\text { driven methods }\end{array}$ & -.06 & .115 & {$[-.14, .02]$} & & & & & \\
\hline & $\begin{array}{l}\text { Alignment different teachers } \rightarrow \text { Effectivity } \\
\text { assignment-driven methods }\end{array}$ & .25 & $<.001$ & {$[.19, .32]$} & & & & & \\
\hline & $\begin{array}{l}\text { Use of teacher-driven methods } \rightarrow \text { Effectivity } \\
\text { assignment-driven methods }\end{array}$ & .05 & .011 & {$[.01, .09]$} & .10 & $<.001$ & -.03 & .317 & .004 \\
\hline & $\begin{array}{l}\text { Hours adult support } \rightarrow \text { Effectivity assignment- } \\
\text { driven methods }\end{array}$ & -.06 & .023 & {$[-.12,-.01]$} & -.10 & $<.001$ & -.01 & .815 & .021 \\
\hline & $\begin{array}{l}\text { Alignment different teachers } \rightarrow \text { Parental satis- } \\
\text { faction with schools' COVID-19 measures }\end{array}$ & .70 & $<.001$ & {$[.64, .76]$} & & & & & \\
\hline & $\begin{array}{l}\text { Use of teacher-driven methods } \rightarrow \text { Parental sat- } \\
\text { isfaction with schools' COVID-19 measures }\end{array}$ & .14 & $<.001$ & {$[.10, .19]$} & .21 & $<.001$ & .05 & .194 & .006 \\
\hline & $\begin{array}{l}\text { Parental competence } \rightarrow \text { Parental satisfaction } \\
\text { with schools' COVID-19 measures }\end{array}$ & .08 & .002 & {$[.03, .13]$} & & & & & \\
\hline & $\begin{array}{l}\text { Hours adult support } \rightarrow \text { Parental satisfaction } \\
\text { with schools' COVID-19 measures }\end{array}$ & -.07 & .003 & {$[-.12,-.02]$} & & & & & \\
\hline
\end{tabular}


Table 3 (continued)

\begin{tabular}{|c|c|c|c|c|c|c|c|c|c|}
\hline & & \multicolumn{3}{|c|}{ Total Sample } & \multicolumn{5}{|c|}{ TD compared to DD } \\
\hline & & \multirow[b]{2}{*}{$\beta$} & \multirow[b]{2}{*}{$p$} & \multirow[b]{2}{*}{$95 \% \mathrm{CI}$} & \multicolumn{2}{|c|}{$\begin{array}{l}\text { TD } \\
n=1442\end{array}$} & \multicolumn{2}{|c|}{$\begin{array}{l}\mathrm{DD} \\
n=775\end{array}$} & \multirow{2}{*}{$\begin{array}{l}\Delta \chi^{2} \\
p\end{array}$} \\
\hline & & & & & $\beta$ & $p$ & $\beta$ & $p$ & \\
\hline \multirow[t]{10}{*}{ Propensity $\rightarrow$ Outcome } & Autonomous motivation $\rightarrow$ Learning time & .13 & $<.001$ & {$[.08, .17]$} & & & & & \\
\hline & Child competence $\rightarrow$ Learning time & -.00 & .893 & {$[-.05, .05]$} & & & & & \\
\hline & $\begin{array}{l}\text { Child's COVID-19 related worries } \rightarrow \text { Effectiv- } \\
\text { ity teacher-driven methods }\end{array}$ & -.12 & .002 & {$[-.19,-.04]$} & & & & & \\
\hline & $\begin{array}{l}\text { Autonomous motivation } \rightarrow \text { Effectivity teacher- } \\
\text { driven methods }\end{array}$ & .29 & $<.001$ & {$[.20, .39]$} & & & & & \\
\hline & $\begin{array}{l}\text { Child competence } \rightarrow \text { Effectivity teacher-driven } \\
\text { methods }\end{array}$ & -.01 & .904 & {$[-.12, .10]$} & & & & & \\
\hline & $\begin{array}{l}\text { Child's COVID- } 19 \text { related worries } \rightarrow \text { Effectiv- } \\
\text { ity assignment-driven methods }\end{array}$ & -.07 & $<.001$ & {$[-.11,-.03]$} & & & & & \\
\hline & $\begin{array}{l}\text { Autonomous motivation } \rightarrow \text { Effectivity } \\
\text { assignment-driven methods }\end{array}$ & .36 & $<.001$ & {$[.30, .41]$} & & & & & \\
\hline & $\begin{array}{l}\text { Child competence } \rightarrow \text { Effectivity assignment- } \\
\text { driven methods }\end{array}$ & .10 & .001 & {$[.04, .16]$} & .03 & .434 & .17 & $<.001$ & .018 \\
\hline & $\begin{array}{l}\text { Autonomous motivation } \rightarrow \text { Parental satisfac- } \\
\text { tion with schools' COVID-19 measures }\end{array}$ & .16 & $<.001$ & {$[.09, .23]$} & & & & & \\
\hline & $\begin{array}{l}\text { Child competence } \rightarrow \text { Parental satisfaction with } \\
\text { schools' COVID-19 measures }\end{array}$ & .07 & .069 & {$[-.01, .14]$} & & & & & \\
\hline
\end{tabular}

95\% CI $=95 \%$ Confidence Interval; Specific parameter estimates for TD and DD group only displayed when a significant difference between both groups was found based on the chi-square difference test $\left(\Delta \chi^{2}\right)$

be established, $\Delta \chi^{2}(16)=110.48, p<.001$. Comparing the structural model between both groups was therefore not possible, since the meaning of the factors was not the same for both groups of children.

\section{Discussion}

The current study examined the learning experiences of children and their parents during the COVID-19 school lockdown in Flanders by applying the Opportunity-Propensity Model (Byrnes, 2020; Byrnes \& Miller, 2007; Wang et al., 2013). This helped structuring a large variety of predictors that affect learner experiences as studied from the perspective of their parents. The study also compared the experiences of children with DD with those of their TD peers and compared children in primary with children in secondary education.

\section{Learning Experiences During the Home Learning Period}

In line with the hypotheses, the results indicated that the remote learning period was more negatively experienced by children with DD, according to their parents. In particular, the used teaching methods (assignment-driven and teacherdriven) were rated as less effective if children had a DD, both in primary and secondary education and the difference between TD and DD was even more pronounced for secondary school children. Further, parents of children with DD were less satisfied with the schools' COVID-19 measures compared to other parents. The sudden switch to remote learning left teachers unprepared, possibly resulting in them being less able to adapt the learning material to the special educational needs of children with DD, which is even more important with more difficult learning content in secondary education and is especially important for assignments in which more independency is expected from the child. The fact that assignment-driven teaching methods were more frequently used (by $96.22 \%$ of teachers) during remote learning than teacher-driven teaching methods (by $25.83 \%$ of teachers) might additionally explain the lower average effectivity of the used teaching methods in DD children. The lower satisfaction in parents of DD children might be a result of them observing more difficulties in their children. Regardless of child diagnosis, the parental satisfaction was lower for parents of secondary school children. 


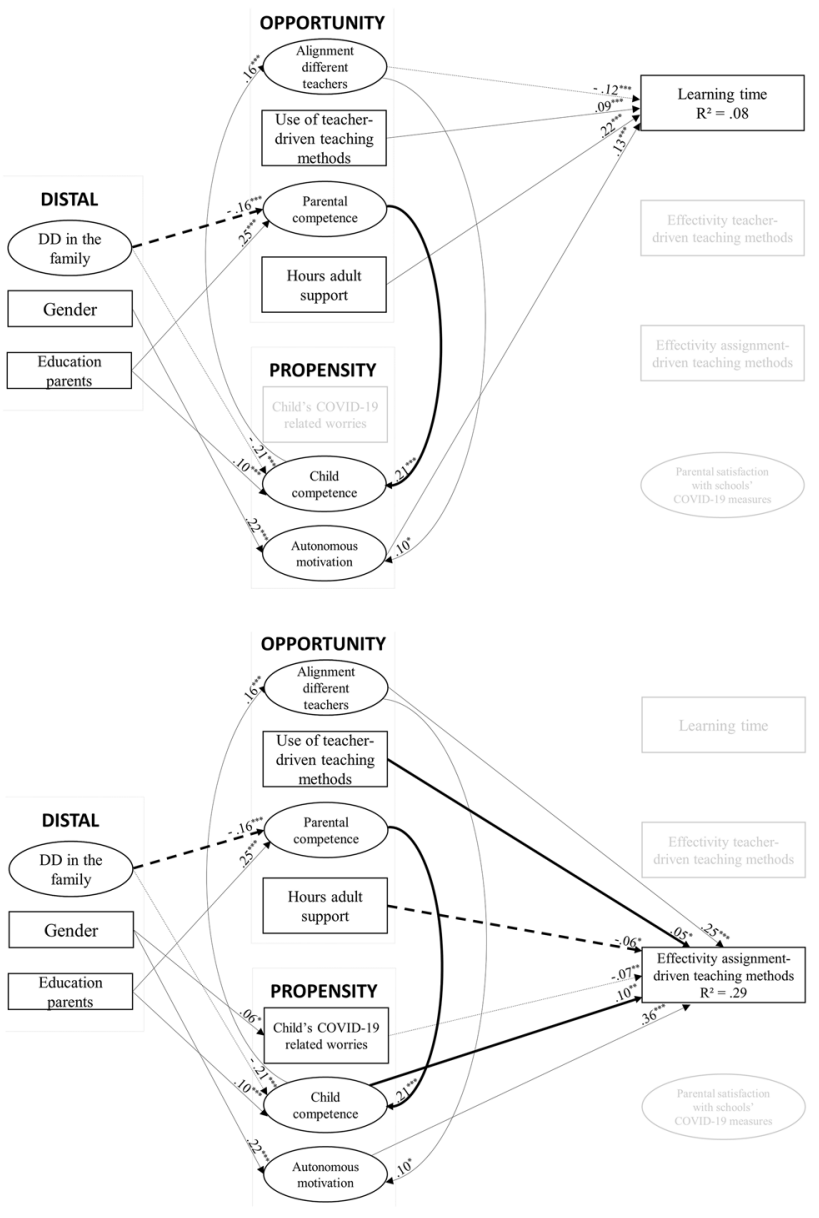

Fig. 2 Results and Parameter Estimates of the Structural Model (Bootstrapped, 1000 Iterations), Split per Outcome Variable for Visual Reasons. ${ }^{*} p<.050,{ }^{* *} p<.010,{ }^{* * *} p<.001$; Fit measures: $\chi^{2}(363)=1718.80, p<.001 ; \mathrm{CFI}=.92 ; \mathrm{RMSEA}=.04 ; \mathrm{SRMR}=.05$, $\mathrm{GFI}=.99, \mathrm{aGFI}=.98$; Full line indicates positive effect, dotted line

Next, the daily learning time spent on schoolwork increased for all children during remote learning, compared to before. But contrary to our expectations, the learning time did not increase more for children with DD than for their TD peers. However, the actual time spent (in hours per day) was higher in DD compared to TD children, both before $\left(M(S D)_{\mathrm{DD}}=1.41(2.72), M(S D)_{\mathrm{TD}}=1.06(2.05)\right)$ and during $\left(M(S D)_{\mathrm{DD}}=2.80(2.99), M(S D)_{\mathrm{TD}}=2.45(2.23)\right)$ the pandemic. Perhaps the work load for these children was already too high, that the maximum time available to spend on schoolwork was already reached. Considering school level and learning time, a higher increase in learning time was found for secondary than for primary school children, even though older students are already more used to work individually for school in the home

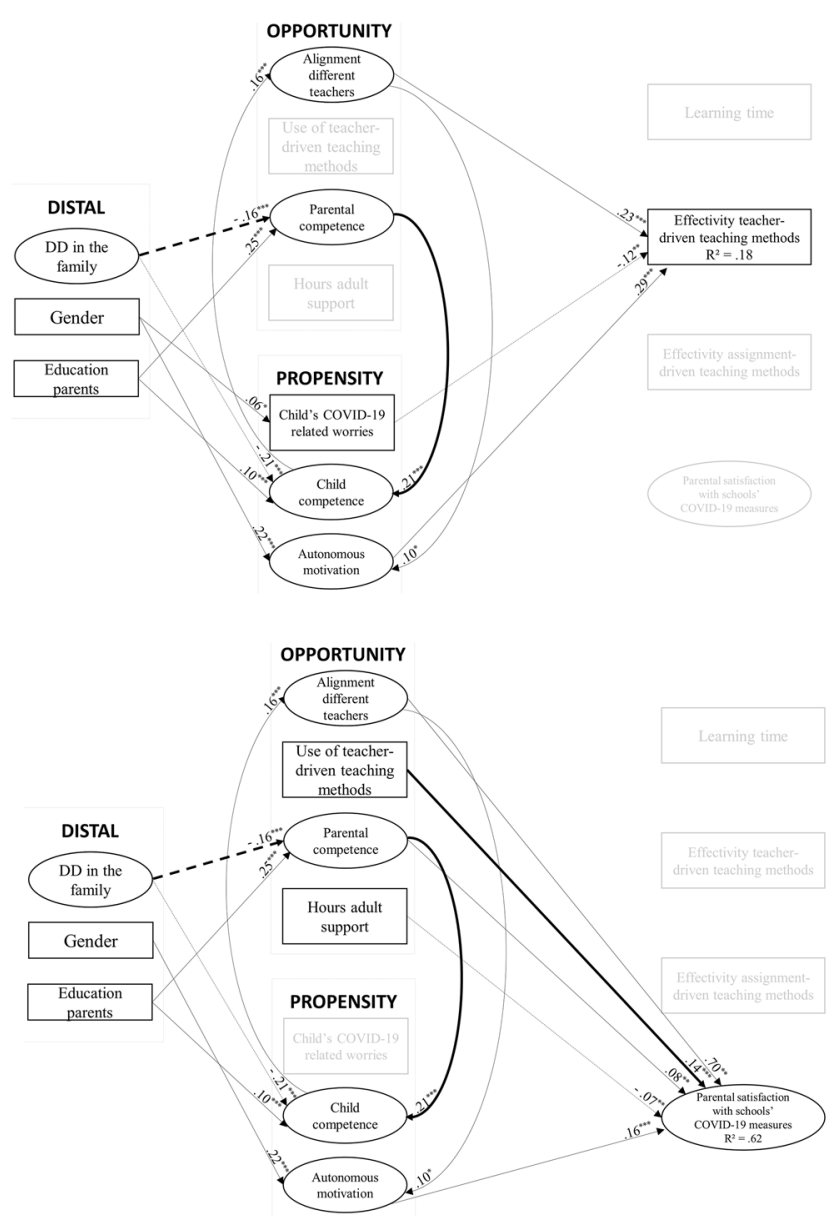

indicates negative effect. Bold lines indicate significant difference between children with developmental disorders and typically developing children. An overview of the parameter estimates, including the differences between both groups of children can be found in Table 3

environment. It is important to mention that there were a lot of individual differences in learning time, in both the TD and the DD group and in both primary and secondary education, possibly related to the available opportunity and propensity variables that might have influenced learning time. We should also consider that the parent-reported learning time does not necessarily reflect the real time children spent on schoolwork as some children will probably have done other things (e.g., surfing on the internet, playing games) while their parents thought they were busy with schoolwork.

Regardless of child diagnosis, there was a higher increase in learning time for girls during the remote teaching period, while both teaching methods were found to be more effective for girls than for boys. 
Our findings confirm and expand other studies conducted in the COVID-19 context, also showing extra difficulties for DD children during the school-closures (Baschenis et al., 2021; Soriano-Ferrer et al., 2021; Zawadka et al., 2021). In order to improve our understanding of why these children experienced extra difficulties, it is important to discuss the predictors of these learning experiences.

\section{Predictors of Learning Experiences During the Home Learning Period and Differences for Children With and Without DD}

Several factors proved to be important in the prediction of the learning experiences of parents and children during the remote learning period. Some of the outcome variables could be better predicted than others: the O-P predictors only explained $8 \%$ of the variance in learning time, while they explained $62 \%$ of the variance in parental satisfaction. Looking at the effectivity of teacher-driven teaching methods, $18 \%$ of the variance was explained and for the effectivity of assignment-driven teaching methods this was $29 \%$. Less significant predictors were observed in parents with DD children than TD children, possibly because some of the opportunity or propensity predictors differed significantly between both groups, immediately affecting their predictive value. Indeed, subsequent analyses revealed that parents of children with DD (compared with TD) rated teachers as being less aligned $\left(M(S D)_{\mathrm{DD}}=14.92(7.04), M(S D)_{\mathrm{DD}}=15.98(7.08)\right.$, $p=.042)$ and found themselves to spend more time supporting their children with schoolwork $\left(M(S D)_{\mathrm{DD}}=6.60(6.86)\right.$, $\left.M(S D)_{\mathrm{TD}}=4.86(6.66), p=.001\right)$. In addition DD children were reported to reflect more COVID-19 related worries $\left(M(S D)_{\mathrm{DD}}=5.13(2.58), M(S D)_{\mathrm{TD}}=4.85(2.39)\right.$, $p=.005)$, to be less competent $\left(M(S D)_{\mathrm{DD}}=13.34(3.43)\right.$, $\left.M(S D)_{\mathrm{TD}}=16.22(2.83), p<.001\right)$ and less autonomously motivated to work for school $\left(M(S D)_{\mathrm{DD}}=1.96(0.81)\right.$, $\left.M(S D)_{\mathrm{TD}}=2.37(0.81), p<.001\right)$.

\section{Distal Factors}

None of the distal factors had a direct effect on the outcome variables, even though we expected that higher educated parents would be more satisfied with the schools' COVID19 measures. However, there was an indirect effect: higher educated parents rated their children as more competent, which was related to parents perceiving multiple teachers as more aligned. This perception of alignment in turn led to higher parental satisfaction.

More DD in the family (i.e., in responding parent, partner and/or siblings) resulted in parents perceiving themselves as less competent. However, this was only the case in the TD group, which might be explained by parents' different frame of reference. Additional analyses revealed thatwhilst not statistically significant - the educational level of parents in the TD group with DD in the family $(M=5.49$, $S D=0.99)$ was somewhat lower than that of the parents in the DD group with additional DD in the family $(M=5.64$, $S D=1.01)$. Further, as expected, the presence of DD in the family was related to lower ratings of child competence. This effect occurred independent of child diagnosis, possibly because of the high heritability of DD with children maybe experiencing subclinical features even without having a formal diagnosis (Barry et al., 2007; Olson, 2011; Snowling \& Melby-Lervåg, 2016; Thapar et al., 2013; Tick et al., 2016; Willcutt et al., 2010). For gender, in line with the hypotheses and previous studies (Elmer et al., 2020; Rajkumar, 2020; Rodríguez-Hidalgo et al., 2020) it was found that girls worried more about the social distancing measures and someone in their environment getting infected with COVID-19 than boys. In addition, girls were more autonomously motivated to work for school than boys, which is in line with findings in the literature (Brouse et al., 2010; Ryan \& Deci, 2000). Next, as hypothesized, higher educated parents rated themselves as more competent to assist their children with schoolwork and rated their children as more competent in school subjects than parents with lower educational levels.

\section{Opportunity Factors}

Perceived alignment of teachers was a significant predictor of all four outcome variables and was also the strongest predictor of parental satisfaction. As expected, when parents perceived teachers being more aligned, daily learning time decreased, teacher-driven and assignment-driven methods were rated as more effective and parents were more satisfied with the schools' COVID-19 measures (e.g., school communication, providing structure, amount of feedback, etc.). When multiple teachers adopt a shared communication channel, children lose less time gathering information from different sources. If the same structure is applied when giving assignments, children understand faster what they have to do and if deadlines are aligned, they lose less time planning what they need to do by when. In addition, it can be assumed that offering tasks and assignments in a more standardized way and using the same structure in for example all online video lessons, makes it easier for children to capture the learning content, allowing goals to be achieved more easily and finally improving the effectivity of these teaching methods. In addition, a more standardized approach is probably associated with more clarity for the children, leading them to ask less questions to their parents and thus improving parental satisfaction with how the school handles the COVID-19 situation. These results are consistent with findings from dual-task research showing that task-performance is facilitated when task-information 
is given in a congruent way as in earlier tasks (Walker et al., 2014) and that task-irrelevant information limits the available cognitive resources for learning (Miller et al., 2019). The results also confirm research about the advantages when adopting shared classroom management approaches (Kaya \& Selvitopu, 2019).

Next, in line with the hypothesis, the use of teacherdriven teaching methods (i.e., recorded lessons, online live group sessions, chatboxes, teaching by telephone), increased children's daily learning time. This could be explained by the higher engagement that is elicited in students by attending live or pre-recorded lessons compared to just reading and completing assignments. In this last case, students might give up easier if the task is unclear or if it gets difficult, reducing the daily learning time and perhaps the effectivity of these assignment-driven teaching methods. Nevertheless, although the teacher-driven methods required more time from the children, they improved the effectivity of assignment-driven teaching methods and increased the parental satisfaction with the schools' COVID-19 measures, at least for TD children. Having a teacher who explains things in videos or in online live sessions makes it easier for children to understand and complete assignments afterwards, improving their effectivity. Also, if parents really "see" the teacher, this is more similar to the traditional teaching situation and might lead to parents finding teachers' to be more involved with their child's learning process. This could make parents feel supported by the school in taking on a teacher role (e.g., Hoover-Dempsey \& Sandler, 1997; Maríñez-Lora \& Quintana, 2009; Park \& Holloway, 2013). Even though children needed more time when schools used teacher-driven teaching methods, we assume that the total time working for school at home during remote learning was still not exceeding the total time spent at schoolwork (time at school + time at home) during regular school times. Furthermore, as long as children work for school for autonomous reasons and as long as they spent more time on schoolwork because the school uses more teacher-driven methods, the higher increase in learning time should not be judged as negative. Whatever the case, the time spent for schoolwork should be kept realistic and overload in learning time should be avoided by ensuring alignment between teachers, and for instance avoiding task-irrelevant-information.

With regards to opportunity factors in the home environment, as expected, it was found that the more time parents spent on supporting their children with schoolwork, the more learning time they reported for their children during remote learning compared to regular school times, and the less effective assignment-driven teaching methods were rated, at least in the TD group. TD children seem to rely more on parental help to complete assignments as compared to regular school times, while there might be less differences in help seeking behavior in DD children when comparing the remote learning period with what happened before. Further, parents who reported to spend more hours supporting their children with schoolwork were less satisfied about the schools' COVID-19 measures, perhaps because these parents perceive their personal investment as taking over too strongly the schools' responsibilities. Next, in line with the expectations, parents who perceived themselves as more competent to support their children with schoolwork were also more satisfied with the school's communication, structure, amount of feedback, quality of feedback, etc. These parents can probably process key information from the school more independently and feel more confident to guide their child's learning process without external support, while this is less obvious for parents who perceive themselves as less competent. These parents might be overwhelmed with the information, need more support and experience more stress.

In contrast with our hypotheses, the hours of adult support were not predictive for the effectivity of teacher-driven methods. A possible explanation is that the help of the teacher is incorporated in teacher-driven methods (e.g., watching videos of the teacher explaining learning content), whereas more independency is expected in assignmentdriven methods, leading to children relying more on their parents. Parental competence did not have a direct effect on the other outcome variables. There was, however, an indirect effect through child competence and the alignment of multiple teachers.

\section{Propensity Factors}

In contrast with the hypotheses, there was a higher increase in learning time during the pandemic (compared to before) for children reflecting more autonomous motives to work for school. Possibly, children that have to rely on themselves or their parents while there is no teacher around (for example when the teacher uses assignment-driven teaching methods) will persevere more to solve inconsistencies or really understand the subject when they are inherently motivated to succeed on the assignment, while children who are less motivated might give up easier as a result of being less passionate about engaging in schoolwork.

Additionally, when parents found their children to be autonomously motivated to work for school, the learning experiences during the remote learning period were rated more positive, which is in line with previous research (e.g., Baten et al., 2020): both teaching methods were rated as more effective and parents were more satisfied with the COVID-19 measures of the school. Children reflecting higher autonomous motivation might rely less on their parents to plan their tasks and assignments, resulting in parents 
perceiving school's communication about assignments and deadlines more positively.

For children of whom their parents reported more COVID-19 related worries, which was more often the case in DD children and in girls, both teacher-driven and assignment-driven teaching methods were rated as less effective. This finding is in line with the hypothesis and with previous research in the pandemic context (Cao et al., 2020; Giusti et al., 2021) and also consistent with prior research in the anxiety and depression domain showing that emotional-cognitive interference negatively influences task performance (Putwain et al., 2010). This can be explained by looking at the lower amount of working memory resources being available for cognitive tasks while worrying (Owens et al., 2012). Worrying about social distancing measures and about someone in the environment getting infected with COVID19 might reduce the cognitive space available to learn school-related content.

Lastly, parents of children with DD, who rated their children as more competent, also found the assignment-driven teaching methods more effective for their children. It can be argued that more competent children are better able to compensate for the difficulties related to their disorder and are as a result able to independently complete assignments while children with DD who are less competent rely more on their parents' help to complete these assignments. For teacher-driven methods, a similar effect was predicted, but not confirmed, maybe because these methods do not directly lead to an academic output product. This is in contrast with completing an assignment following assignment-driven methods. For TD children and for the other hypotheses related to child competence and the outcome variables, we only observed indirect effects of child competence on children's learning experiences. These effects were consistently mediated through parental perceptions of teacher alignment (see opportunity factors), with parents indicating more alignment if they found their children more competent, finally resulting in a higher effectivity of teacher-driven methods, less learning time and more parental satisfaction. However, this is but a first possible explanation. We have to take into account that the current study measured all variables concurrently and the direction of the relationship was derived from the O-P Model. Other pathways might be possible as explained in the limitations section.

In contrast to the majority of previous studies (e.g., Byrnes, 2020; Byrnes \& Wasik, 2009), the impact of the opportunity factors in the current study was larger than the effects of the propensity factors. However, previous O-P studies focused on academic achievement as an outcome variable, while the current study related the predictors in the model to broader learning experiences. In addition, the biggest differences between the remote and the regular learning situation are observed at the opportunity factors. It is therefore logical that e.g., daily learning time (reflecting the difference in learning time between regular and remote teaching) is mostly influenced by opportunity factors. The same holds for parental satisfaction with the schools COVID-19 measures (i.e., opportunity factors). Finally, the learning experiences of the children were not measured directly, but through parents that explicitly belong to the opportunity side of the O-P Model.

\section{Practical Implications}

The results of the current study can be translated into practical implications for DD/TD children and for regular and future periods of (forced) remote learning. Overall, the alignment of different teachers and children's autonomous motivation seem to be the two most important predictors of our outcome variables. A first recommendation is thus that in order to improve learning experiences, it seems critical for teachers to communicate with each other, to align deadlines and rules, and to share software/tools and communication channels. This is not only recommended for remote learning practices, but also for regular school times in which the removal of task-irrelevant burden might be beneficial for all children, but especially for DD children experiencing difficulties with executive functions (e.g., De Weerdt et al., 2013).

Second, it is worthwhile, especially for boys (Brouse et al., 2010; Ryan \& Deci, 2000) and in secondary education (De Naeghel et al., 2016; Gnambs \& Hanfstingl, 2016) to boost children's autonomous motives to work for school. Parents and teachers should tickle children's interest and curiosity for schoolwork. This can be achieved by adopting a need-supportive teaching/parenting style in order to improve the satisfaction of autonomy, competence and relatedness, three basic and essential psychological needs that have been related to a lot of positive outcomes (e.g., Aelterman et al., 2014; Cheon et al., 2020; Niemiec \& Coulson, 2017; Niemiec \& Ryan, 2009; Vansteenkiste et al., 2020) In particular, such a need-supportive style is characterized by connecting the tasks and learning content to students' personal goals and interests (Assor et al., 2002), by using an inviting instead of a pressuring (e.g., "you should") communication style (Baten et al., 2020; Reeve, 2009, 2016) and by building in choices, by for example offering different assignments for children to choose from (Reeve, 2009, 2016). Additionally, explaining children why learning activities are self-relevant and offering a meaningful rationale for learning activities (Jang, 2008; Reeve et al., 2002; Steingut et al., 2017) will increase engagement and willingness to learn. In a remote learning context for example, it can be helpful to explain children why learning in the classroom context is not possible, to make sure that children, even when not physically able to see each other, have virtual possibilities to socially 
connect (with others and teachers), to provide a structured learning environment in which the teacher guides the learning process and offers choices, rather than adopting only a task and assignment-driven teaching approach in which the teacher communicates assignments and deadlines without children ever having 'real' contact with the teacher and fellow students.

Related to this, a third implication is that teacher-driven methods should be a central element in shaping teaching practices. Whether during regular school times or for remote teaching, (real)-life engagement of the teacher is crucial for the quality of education and the parental satisfaction. When the teacher guides the learning process, it is easier to take into account individual characteristics of children such as executive functioning deficits in children with DD (e.g., Baten \& Desoete, 2018; Diamantopoulou et al., 2007; Grigorenko et al., 2019; Imeraj et al., 2013), by for example dividing the learning content into smaller units, adapting the learning tempo, etc., which in turn might lead to more positive learning experiences and possibly better academic performances (Klingner \& Vaughn, 1999; Raggi \& Chronis, 2006). In addition, assignment-driven methods were found to be more effective when they are accompanied by teacher-driven methods. This suggests that a blend is useful in adopting teaching methods to be able to cater for the diversity in learner needs. It is furthermore strongly recommended that informative feedback is provided after learners hand in their assignment (Bryan \& Burstein, 2004; Salend \& Schliff, 1989; Xu, 2011). For children diagnosed with DD, we additionally recommend continuing extra support with specific therapy (Aishworiya \& Kang, 2021), providing enough structure and adopting standardized routine. This is critical since for these children the positive effects of teacher-driven methods on learning experiences could not be confirmed. In combination with extra support and therapy, it is important to look in future research for other factors that affect the learning experiences of DD children.

Lastly, in times of uncertainty, such as a pandemic, it is important that children can rely on someone to talk about their uncertainties and worries. We acknowledge that this is not self-evident and very dependent on the home situation. Teachers awareness should be raised about this additional need; especially when children can rely less on their parents (e.g., health-care professionals who had to work longer hours during the pandemic). Making sure these children can talk with someone about their worries might help to free working-memory resources to achieve their learning goals (Owens et al., 2012). We can assume that this finding is not only relevant for pandemic-related worries but also for other problems and uncertainties of DD children; for example feelings of inadequacy of children diagnosed with RLD during regular school times (Baschenis et al., 2021).

\section{Limitations, Strengths and Suggestions for Future Research}

This study reflects limitations that require further discussion. First, not all potentially important predictors could be examined in this study and other variables are likely also of influence. Second, all variables in this study were measured through parents, even when these were related to their children or to the school/teacher. Even though parents might be better apt to give their information and opinion as to their child; this might have caused bias. Nevertheless, parental input was the only way to involve a large number of participants in the middle of the pandemic, within the time window of the current study. In future studies, some variables and processes should be mapped on the base of input from children, schools/teachers and parents. At the same time, a prospective study could be set up, instead of a retrospective study; e.g., by using diaries, academic tests to measure child competence, panel ratings, and others.

Third, the cross-sectional nature of the study does not allow drawing causal inferences. All variables were measured concurrently and the measurement did not account for the typical time dimension that is at the base of the O-P Model. However, based on previous literature, some relations appear plausible and the direction of the predictions is in line with the Opportunity-Propensity Model (Byrnes, 2020; Byrnes \& Miller, 2007; Wang et al., 2013). Nevertheless, the results should be interpreted with caution and future research should explore and test other interrelations. For example, parents' perception of the alignment of teachers could have been considered an outcome (instead of an opportunity) variable, and be predicted by parental competence. Similarly, the parental rating of the effectivity of teaching methods might have a bigger impact on the parent-reported COVID-19 worries for the child than the other way around. It would be interesting to examine some of these relations more in detail by using other research methods. When looking at the effect of autonomous motivation, for example, an intervention study and a related experimental evaluative design could be set-up to find out if improving children's autonomous motives to work for school would improve the effectivity of both teaching methods for these children. If so, this could be beneficial for children with $\mathrm{DD}$, especially in secondary education, for whom both teaching methods were found to be less effective, compared to TD children.

Fourth, because the latent constructs in the current study were found to be different in meaning in primary and secondary education, it is less feasible to compare the predictors of children's learning experiences between both school levels. This makes sense, as primary schools are organized differently than secondary schools. The amount of structure a school provides will probably be of higher importance in 
view of parental satisfaction in secondary than in primary school. The difficulty level of the learning objectives being pursued helps explaining this. In order to specify guidelines and recommendations based on school level, a bigger sample size would have been convenient in order to be able to run the model separately for both school levels.

Next, and in line with the previous limitation, we were only able to compare the structural model for a group of children with DD with a group of TD children. To gain insight into the difficulties faced by children with specific $\mathrm{DD}$, it would be interesting to compare the different DD groups-for example children with and without ASD-for the structural model. However, multi-group analysis on a SEM-model of this size requires very big sample sizes per DD-group. This is a challenging design characteristic for future studies.

Another limitation is that more than $50 \%$ of the participating parents in the current study had at least a Bachelor's degree. This might be due to the online nature of the study, with some families having easier access to the internet than others. A more diverse sample might have yielded other significant relationships.

An important strength of this study is the large sample size, with the children of interest being of a diverse age range and going to both primary and secondary education. In addition, there were proportionally a lot of parents of children with DD that took part in the survey and this made it possible to-even though in an exploratory way - examine differences between different DD's. With our exploratory analysis we built a foundation for future studies that can compare the several DD in more detail in order to refine the recommendations of our current study that now fit in a Universal Design for Learning (Carrington et al., 2020; Kennette \& Wilson, 2019) approach.

Another strength is that the questionnaire - even though retrospectively - was filled out by the parents very close to the period of interest of the current study. Considering that this period was already filled with a lot of challenges and difficulties for the parents, this is a particularly strong advantage of the current data. Another strength is that this study was grounded in the validated framework of the Opportunity-Propensity Model (Byrnes, 2020; Byrnes \& Miller, 2007; Wang et al., 2013), taking into account a holistic picture that embraces many factors at the same time and therefore allowing to draw stronger conclusions about which predictors are of importance when evaluating children's learning experiences.

Given the time frame of the current study we did not consider learning performance as an outcome variable but rather investigated associated learning experiences. Future studies can add this variable to the design and enrich as such the picture being offered by the O-P Model.

\section{Conclusion}

The current study demonstrated that the home learning period was more negatively experienced by children with $\mathrm{DD}$, according to their parents. In particular, we found that the teaching methods schools used during remote learning were less effective for DD than for TD children, especially in secondary education. In addition, independent of school level, parents of children with DD were less satisfied with the COVID-19 measures taken by the school than parents of other children.

Further, the current study indicated that alignment between teachers (opportunity factor) and a high level of autonomous motivation in children (propensity factor) were the most important predictors of these learning experiences. In TD children, the use of more teacher-driven teaching methods (opportunity factor) such as live online lessons or recorded lessons furthermore improved children's learning experiences and parental satisfaction. Less predictors were found to explain the learning experiences of children with DD, which may indicate that other factors play a larger role in this group. Continuing specific therapy or support for these children in times of schoolclosures may be necessary to avoid that they fall even further behind (Aishworiya \& Kang, 2021).

We recommend teachers to align their classroom management practices and teaching approaches as much as possible (deadline, structure, communication channel, etc.) and to use sufficient teacher-driven methods (online lessons, recorded lessons, chatboxes, etc.), both in the general classroom practice and during remote learning. Finally, we advise both parents and teachers to foster children's autonomous motivation by adopting an autonomysupportive approach within the family and academic context and to ensure that the child gets adequate emotional support to turn to in times of need.

\section{Appendix}

\section{Part 1: Pre-Processing of Data}

Parents of children with and without DD could fill out the questionnaire. The information letter at the beginning of the questionnaire summarized the inclusion criteria, however it was not impossible for other parents to participate. In that case, these data were excluded from the data-analysis. The inclusion criteria comprised having at least one school-aged child with or without DD between 5 and 18 years old and being a resident of Flanders (Dutch speaking-part of Belgium). In total, 3506 parents started to fill out the survey. From this group, 357 did not provide 
Table 4 Demographical Data $(M(S D)$ or $n(\%))$ of the Typically Developing Children (TD) and Children with Developmental Disorders (DD)

\begin{tabular}{|c|c|c|c|c|c|c|c|}
\hline & $\begin{array}{l}\text { TD } \\
(n=1443)\end{array}$ & $\begin{array}{l}\text { ASD } \\
(n=344)\end{array}$ & $\begin{array}{l}\text { RLD } \\
(n=274)\end{array}$ & $\begin{array}{l}\text { ADHD } \\
(n=259)\end{array}$ & $\begin{array}{l}\text { MLD } \\
(n=134)\end{array}$ & $\begin{array}{l}\text { DCD } \\
(n=123)\end{array}$ & $\begin{array}{l}\text { DLD } \\
(n=61)\end{array}$ \\
\hline Age & $9.75(3.12)$ & $10.74(3.12)$ & $11.66(2.72)$ & $10.77(3.01)$ & $11.90(2.67)$ & $10.66(3.09)$ & $9.84(2.62)$ \\
\hline \multicolumn{8}{|l|}{ Gender } \\
\hline Boy & $716(49.60 \%)$ & $250(72.70 \%)$ & $164(59.90 \%)$ & $193(74.50 \%)$ & $45(33.60 \%)$ & $97(78.90 \%)$ & $38(62.30 \%)$ \\
\hline Girl & $727(50.40 \%)$ & $94(27.30 \%)$ & $109(39.80 \%)$ & $66(25.50 \%)$ & $89(66.40 \%)$ & $26(21.10 \%)$ & $23(37.70 \%)$ \\
\hline \multicolumn{8}{|l|}{ Type of Education } \\
\hline Regular education & $1441(99.90 \%)$ & $264(76.70 \%)$ & $262(95.60 \%)$ & $222(85.70 \%)$ & $127(94.80 \%)$ & $95(77.20 \%)$ & $47(77.00 \%)$ \\
\hline Special education & $2(0.10 \%)$ & $80(23.30 \%)$ & $12(4.40 \%)$ & $37(14.30 \%)$ & $7(5.20 \%)$ & $28(22.80 \%)$ & $14(23.00 \%)$ \\
\hline \multicolumn{8}{|l|}{ Grade } \\
\hline 1 & $298(20.70 \%)$ & $42(12.20 \%)$ & $5(1.80 \%)$ & $27(10.40 \%)$ & $3(2.20 \%)$ & $17(13.80 \%)$ & $10(16.40 \%)$ \\
\hline 2 & $227(15.70 \%)$ & $30(8.70 \%)$ & $13(4.70 \%)$ & $25(9.70 \%)$ & $3(2.20 \%)$ & $10(8.10 \%)$ & $10(16.40 \%)$ \\
\hline 3 & $168(11.60 \%)$ & $42(12.20 \%)$ & $32(11.70 \%)$ & $29(11.20 \%)$ & $14(10.40 \%)$ & $20(16.30 \%)$ & $5(8.20 \%)$ \\
\hline 4 & $129(8.90 \%)$ & $48(14.00 \%)$ & $36(13.10 \%)$ & $34(13.10 \%)$ & $20(14.90 \%)$ & $16(13.00 \%)$ & $9(14.80 \%)$ \\
\hline 5 & $147(10.20 \%)$ & $41(11.90 \%)$ & $36(13.10 \%)$ & $34(13.10 \%)$ & $14(10.40 \%)$ & $12(9.80 \%)$ & $10(16.40 \%)$ \\
\hline 6 & $116(8.00 \%)$ & $27(7.80 \%)$ & $31(11.30 \%)$ & $19(7.30 \%)$ & $18(13.40 \%)$ & $6(4.90 \%)$ & $5(8.20 \%)$ \\
\hline 7 & $111(7.70 \%)$ & $27(7.80 \%)$ & $33(12.00 \%)$ & $26(10.00 \%)$ & $14(10.40 \%)$ & $12(9.80 \%)$ & $6(9.80 \%)$ \\
\hline 8 & $60(4.20 \%)$ & $23(6.70 \%)$ & $33(12.00 \%)$ & $22(8.50 \%)$ & $17(12.70 \%)$ & $9(7.30 \%)$ & $3(4.90 \%)$ \\
\hline 9 & $70(4.90 \%)$ & $29(8.40 \%)$ & $22(8.00 \%)$ & $22(8.50 \%)$ & $16(11.90 \%)$ & $11(8.90 \%)$ & $2(3.30 \%)$ \\
\hline 10 & $45(3.10 \%)$ & $11(3.20 \%)$ & $10(3.60 \%)$ & $7(2.70 \%)$ & $5(3.70 \%)$ & $2(1.60 \%)$ & $0(0.00 \%)$ \\
\hline 11 & $46(3.20 \%)$ & $17(4.90 \%)$ & $14(5.10 \%)$ & $9(3.50 \%)$ & $8(6.00 \%)$ & $5(4.10 \%)$ & $1(1.60 \%)$ \\
\hline 12 & $26(1.80 \%)$ & $7(2.00 \%)$ & $9(3.30 \%)$ & $5(1.90 \%)$ & $2(1.50 \%)$ & $3(2.40 \%)$ & $0(0.00 \%)$ \\
\hline \multicolumn{8}{|c|}{ Comorbidity (>1 DD) } \\
\hline No & $1443(100 \%)$ & $150(43.60 \%)$ & $170(62.00 \%)$ & $94(36.3 \%)$ & $77(57.5 \%)$ & $24(19.50 \%)$ & $24(39.30 \%)$ \\
\hline Yes & $0(0.00 \%)$ & $194(56.40 \%)$ & $104(38.00 \%)$ & $165(63.7 \%)$ & $57(42.5 \%)$ & $99(80.50 \%)$ & $37(60.70 \%)$ \\
\hline
\end{tabular}

$M$ Mean, $S D$ Standard Deviation, $T D$ Typically Developing, $D D$ Developmental Disorder, $A S D$ Autism Spectrum Disorder, $R L D$ Reading Learning Disabilities, $A D H D$ Attention Deficit Hyperactivity Disorder, $M L D$ Mathematical Learning Disabilities, $D C D$ Developmental Coordination Disorder, $D L D$ Developmental Language Disorder

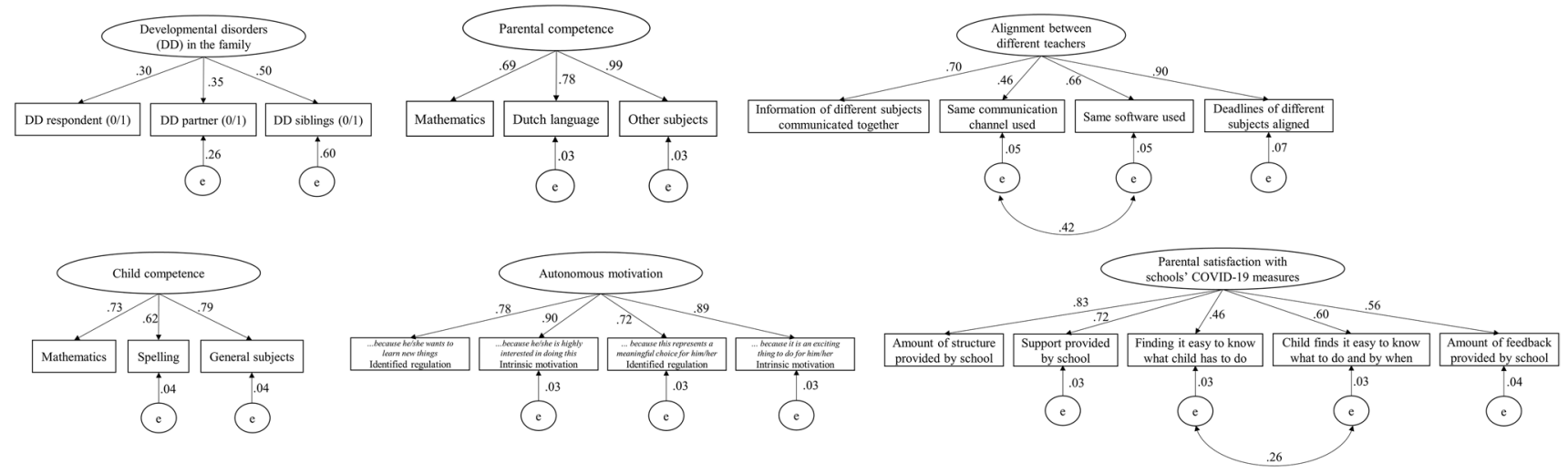

Fig. 3 Confirmatory Factor Analysis Results. Parameter estimates are standardized, all were significant, $p<.001$. First indicator always fixed to 1 for estimation. $\mathrm{e}=$ standardized errors. $\mathrm{DD}=$ developmental disorders

any answers to the questions, 14 only provided information on themselves but not on their child, 317 only provided demographic information but nothing about the current COVID-19 situation and 29 were residents from the Netherlands. These participants were all excluded. Because the current paper only focused on children in primary and secondary education, data of children in the third grade of kindergarten $(n=85)$ were also excluded. In addition, the grade of 50 other participants was classified by their parents as 'other', including for example children in the 
younger years of kindergarten, children in multigrade classes and children in higher education such as bachelor students. These were also excluded. Regarding child diagnosis, a list of the DD of interest in the current study was presented to the parents (i.e., ASD, RLD, ADHD, MLD, DCD, DLD). Parents were asked if their child had one of more of these diagnoses. In addition, they could also indicate that their child had an 'other' diagnosis, after which they had the possibility to specify with an open-ended question. Children with other diagnoses $(n=421)$ were excluded from data-analysis. Finally, parents were asked about their child's type of education (i.e., regular, special or other). Data of parents indicating 'other' $(n=11)$ were also excluded. This resulted in a final sample size of 2222. In this dataset, implausible values were deleted or replaced. More specifically, the following values were considered as missing values because these were probably typos: having more than 20 children living at home $(n=3)$, parents indicating themselves or their partner to be younger than 16 or older than $99(n=75)$, children having more than $100 \mathrm{~h}$ per week of specific support or therapy $(n=4)$, adults supporting their child with schoolwork for more than $40 \mathrm{~h}$ per week $(n=7)$. In addition, for two participants, the child's age was considered as missing because of a large discrepancy between the age and the grade of the child $(n=2)$. Finally, for two respondents and two of their partners the year of birth was given instead of age, so the corresponding age was calculated and used as a value. This was also the case for one of the children.

\section{Part 2: Group Differences Regarding Age, Gender, School Type and School Level}

See Table 4 for demographical details of the children. Children's age was significantly higher in the DD group $(M=11.02, S D=3.03)$ than in the TD group $(M=9.75$, $\left.S D=3.12), F(1,2219)=85.11, p<.001, \eta_{\mathrm{p}}^{2}=.04\right)$. There was no significant age difference between children with one $(M=11.06, S D=3.06)$ or more diagnoses $(M=10.93$, $S D=2.97), F(1,777)=0.34, p=.559, \eta_{\mathrm{p}}^{2}=.00$. There were significantly more boys compared to girls in the DD group $\left(n_{\text {boy }}=506, n_{\text {girl }}=272\right.$, ratio $\left.=1.86\right)$ than in the TD group $\left(n_{\text {boy }}=714, n_{\text {girl }}=729\right.$, ratio $\left.=0.98\right), \chi^{2}(2)=51.26, p<.001$. Additionally, the boy-girl ratio was significantly higher $\left(n_{\text {boy }}=195, n_{\text {girl }}=78\right.$, ratio $\left.=2.50\right)$ in the children with comorbid DD than in the children with only one DD $\left(n_{\text {boy }}=311, n_{\text {girl }}=194\right.$, ratio $\left.=1.60\right), \chi^{2}(2)=8.10, p=.017$. The ratio regular compared to special education was significantly different in the DD group $\left(n_{\text {regular }}=692, n_{\text {special }}=87\right.$, ratio $=7.95)$ in comparison to the TD group $\left(n_{\text {regular }}=1441\right.$, $n_{\text {special }}=2$, ratio $\left.=720.5\right), \chi^{2}(1)=160.06, p<.001$. Moreover, if children had comorbid DD, significantly more of them

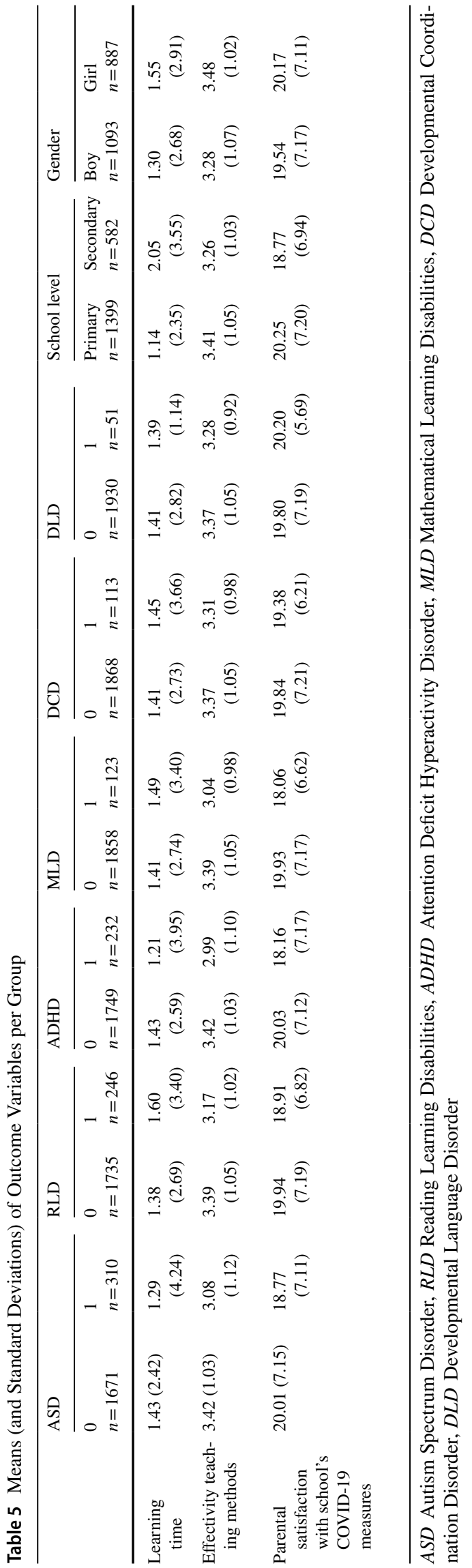


Table 6 Multivariate Effects of Several Developmental Disorders (DD) and School Level (Primary/Secondary) on Outcome Variables

\begin{tabular}{llll}
\hline & $F(3,1963)$ & $p$ & $\eta_{p}^{2}$ \\
\hline ASD (0/1) & 4.35 & .005 & .01 \\
RLD (0/1) & 1.19 & .314 & .00 \\
ADHD (0/1) & 6.91 & $<.001$ & .01 \\
MLD (0/1) & 3.09 & .026 & .01 \\
DCD (0/1) & 1.66 & .173 & .00 \\
DLD (0/1) & 1.11 & .343 & .00 \\
School level (Primary/Secondary) & 1.94 & .121 & .00 \\
ASD x School level & 2.61 & .050 & .00 \\
RLD x School level & 0.98 & .400 & .00 \\
ADHD x School level & 2.37 & .069 & .00 \\
MLD x School level & 1.08 & .356 & .00 \\
DCD x School level & 1.30 & .272 & .00 \\
DLD x School level & 1.26 & .286 & .00 \\
Gender (Boy/Girl) & 5.69 & .001 & .01 \\
\hline
\end{tabular}

$A S D$ Autism Spectrum Disorder, RLD Reading Learning Disabilities, $A D H D$ Attention Deficit Hyperactivity Disorder, $M L D$ Mathematical Learning Disabilities, $D C D$ Developmental Coordination Disorder, $D L D$ Developmental Language Disorder, $\eta_{p}^{2}=$ partial eta squared (effect size)

attended special education $(n=215)$ than regular education $(n=58 ;$ ratio $=3.71)$ in comparison with children with only one DD $\left(n_{\text {regular }}=477, n_{\text {special }}=29\right.$, ratio $\left.=16.45\right)$, $\chi^{2}(1)=43.02, p<.001$. There was a significant difference in the ratio primary compared to secondary education between the DD group $\left(n_{\text {primary }}=489, n_{\text {secondary }}=290\right.$, ratio $\left.=1.69\right)$ and the TD group $\left(n_{\text {primary }}=1085, n_{\text {secondary }}=358\right.$, ratio $=3.03), \chi^{2}(1)=37.76, p<.001$. Within the $\mathrm{DD}$ group, there was no significant difference in the ratio primary-secondary education for children with comorbid DD $\left(n_{\text {primary }}=178, n_{\text {secondary }}=95\right.$, ratio $\left.=1.87\right)$, compared to children with only one DD $\left(n_{\text {primary }}=311, n_{\text {secondary }}=195\right.$, ratio $=1.60), \chi^{2}(1)=1.06, p=.303$.

\section{Part 3: Preliminary Analyses: Confirmatory Factor Analysis (CFA)}

Before conducting Confirmatory Factor Analysis (CFA) for all latent variables in the model (DD in the family, parental competence, alignment between different teachers, child competence, autonomous motivation and parental satisfaction with schools' COVID-19 measures), the indicators per construct were correlated with each other to detect highly correlated items. For the alignment between different teachers, there was a high correlation $(r=0.72, p<.001)$ between parents rating about teachers following the same structure $(S D=3.11)$ and parents rating about teachers having aligned the deadlines of the different subjects $(S D=3.34)$, with the

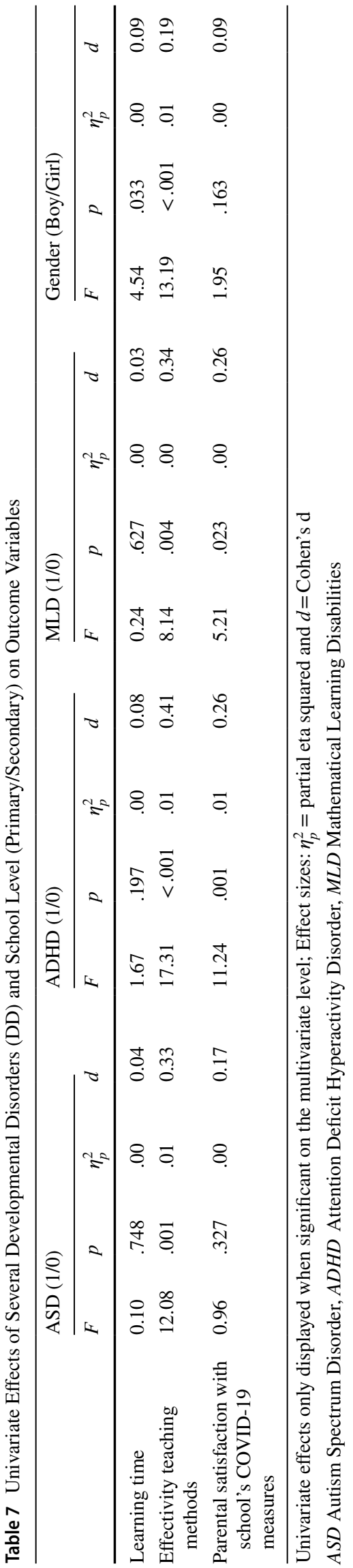


latter being retained in the model (highest SD). For child competence, there was a high correlation $(r=.78, p<.001)$ between the competence for reading $(S D=2.02)$ and the competence for spelling $(S D=2.18)$, with the competence for spelling being retained in the model. For the eight items of autonomous motivation, when a high correlation $(r \geq .70)$ between items was observed, it was additionally taken into account that this scale is a combination of two subscales (identified regulation and intrinsic motivation). When omitting items, items with the highest standard deviation were retained. However, it was preserved that each subscale would still be represented in the final set of items with at least two indicators. As such, the total of eight items was reduced to four items (two from each subscale): "My child was motivated to work for school during the home learning period because ..." "he/she wants to learn new things", "this represents a meaningful choice for him/her" (identified regulation), "he/she is highly interest in doing this", "it's an exciting thing to do for him/her" (intrinsic motivation). Finally, for parental satisfaction with COVID-19 measures of the school, there was a high correlation $(r=.70, p<.001)$ between parental satisfaction with the amount of feedback their child received $(S D=3.68)$ and the satisfaction about the feedback being clear and helpful $(S D=3.66)$, with the first item being retained in the model. Also the parental satisfaction with the school's communication $(S D=2.49)$ and the parental satisfaction about the amount of structure the school provided $(S D=2.78)$ were highly correlated $(r=.76$, $p<.001)$, with parental satisfaction about the amount of structure provided by the school being retained in the model. The final set of items for each of the six constructs where then used in six separate CFA's. Fitting the latent constructs (developmental disorders in the family, parental competence and child competence) resulted in a perfect fit, $\chi^{2}(0)=0.00 ; \mathrm{CFI}=1.00$; RMSEA $=.00 ; \mathrm{SRMR}=.00$, $\mathrm{GFI}=1.00, \mathrm{aGFI}=1.00$. For the alignment between different teachers, the CFA fitting results indicated the following fit measures: $\chi^{2}(2)=123.26, p<.001 ; \mathrm{CFI}=.90$; $\mathrm{RMSEA}=.26$; $\mathrm{SRMR}=.05, \mathrm{GFI}=.99, \mathrm{aGFI}=.90$. Modification indices (mi) revealed that allowing covariance between the errors of parents rating about different teachers using the same communication channel and different teachers using the same software would improve the original chi-square value with 133.61 (at least $20 \%$ improvement). As this makes theoretically sense, these errors were allowed to covariate, resulting in the following final fit measures: $\chi^{2}(1)=0.33, p=.564$; $\mathrm{CFI}=1.00 ; \mathrm{RMSEA}=.00 ; \mathrm{SRMR}=.00, \mathrm{GFI}=1.00$, $\mathrm{aGFI}=1.00$. For the construct of autonomous motivation, fit measures indicated a good fit, $\chi^{2}(2)=9.94, p=.007$; $\mathrm{CFI}=1.00 ; \mathrm{RMSEA}=.04 ; \mathrm{SRMR}=.01, \mathrm{GFI}=1.00$, $\mathrm{aGFI}=1.00$. However, mi's revealed that allowing the errors of the two intrinsic motivation items to covariate, would improve the original chi-square value with at least
$20 \%$ (mi: 3.07). Nonetheless, when allowing this covariance in the model, the results indicated this covariance to be non-significant $(p=.078)$, so the original model without the covariance was retained. Finally, for the parental satisfaction with schools' COVID-19 measures, a good fit was obtained, $\chi^{2}(5)=146.18, p<.001 ; \mathrm{CFI}=.95 ; \mathrm{RMSEA}=.12$; $\mathrm{SRMR}=.04, \mathrm{GFI}=.99, \mathrm{aGFI}=.98$. Yet, allowing the errors of "finding it easy to know what my child has to do" and "my child finds it easy to know what to do and by when" to covariate, improved the original chi-square with at least $20 \%$ (mi: $115.85)$. Since this was theoretically arguable, this model adaption was made, resulting in a final fit of $\chi^{2}(4)=32.80$, $p<.001 ; \mathrm{CFI}=.99 ; \mathrm{RMSEA}=.06 ; \mathrm{SRMR}=.02, \mathrm{GFI}=1.00$, $\mathrm{aGFI}=.99$. As a last preliminary check, the fit for all six separate CFA's combined was calculated. Results indicated a good fit, $\chi^{2}(191)=914.78, p<.001 ; \mathrm{CFI}=.95$; RMSEA $=.04 ;$ SRMR $=0.04, \mathrm{GFI}=.99$, aGFI $=.99$. Standardized parameter estimates and standardized errors for each of the CFA's can be found in Fig. 3 .

\section{Part 4: Research Question 1: Additional Analysis: Multivariate Results}

In an exploratory way, it was investigated if there were differences on the outcome variables for the several DD included in this research. The MANCOVA with all separate DD's included as dummy variables in the analysis revealed that $\operatorname{ASD}(0 / 1), F(3,1963)=4.35, p=.005, \eta_{p}^{2}=.01$, ADHD $(0 / 1), F(3,1963)=6.91, p<.001, \eta_{p}^{2}=.01$, and $\operatorname{MLD}(0 / 1)$, $F(3,1963)=3.09, p=.026, \eta_{p}^{2}=.01$ were significantly impacting the outcome variables on the multivariate level. These effects emerged when controlling for the multivariate effect of gender, $F(3,1963)=5.69, p=.001, \eta_{p}^{2}=.01$. Means and standard deviations are reported in Table 5, the multivariate effects are reported in Table 6 and the follow-up univariate effects are reported in Table 7.

Parents of children with ASD, ADHD and MLD rated the used teaching methods as less effective than parents of children without these DD. In addition, parents of children with ADHD and MLD were less satisfied with the schools' COVID-19 measures than other parents. With regards to gender, a higher increase in learning time was reported for girls compared to boys and both teaching methods were rated as being more effective for girls than for boys. The other multivariate results (effects of the other DD (i.e., RLD, DCD, DLD), effects of school level and the interaction effects of all DD with school level) were non-significant. As such, follow-up univariate results are not discussed.

Acknowledgments FV is supported by the Ghent University Special Research Fund (01D03219). 
Author Contributions EB: Conceptualization and Design/Recruitment/ Survey Preparation/Data Collection/Data Analysis/Writing - Original Draft/Visualization; FV: Conceptualization and Design/Recruitment/ Survey Preparation/Data Collection/Writing - Review \& Editing; MM: Conceptualization and Design/Recruitment/Survey Preparation/Data Collection/Writing - Review \& Editing; MV: Data Analysis/Writing - Review \& Editing; AD: Conceptualization and Design/Recruitment/ Survey Preparation/Data Collection/Writing - Review \& Editing/ Supervision; PW: Conceptualization and Design/Recruitment/Survey Preparation/Data Collection/Writing - Review \& Editing/Supervision. All authors read and approved the final manuscript.

\section{Declarations}

Conflict of interest The authors declare that they have no conflict of interest.

Informed Consent Informed consent was obtained from all individual participants included in the study. The study was approved by the ethics committee of the Faculty of Psychology and Educational Sciences, Ghent University (Belgium). Participation was voluntary and the confidentiality of the child and caregiver(s) was protected.

\section{References}

Ackerman, B. P., \& Brown, E. D. (2010). Physical and psychosocial turmoil in the home and cognitive development. In Chaos and its influence on children's development: An ecological perspective. (pp. 35-47). American Psychological Association. https://doi. org/10.1037/12057-003

Aelterman, N., Vansteenkiste, M., Van Den Berghe, L., De Meyer, J., \& Haerens, L. (2014). Fostering a need-supportive teaching style: Intervention effects on physical education teachers' beliefs and teaching behaviors. Journal of Sport \& Exercise Psychology, 36(6), 595-609. https://doi.org/10.1123/jsep.2013-0229

Ahn, J., \& McEachin, A. (2017). Student enrollment patterns and achievement in Ohio's online charter schools. Educational Researcher, 46(1), 44-57. https://doi.org/10.3102/0013189X17 692999

Aishworiya, R., \& Kang, Y. Q. (2021). Including children with developmental disabilities in the equation during this COVID-19 pandemic. Journal of Autism and Developmental Disorders, 51(6), 2155-2158. https://doi.org/10.1007/s10803-020-04670-6

Alfaro, E. C., Umaña-Taylor, A. J., Gonzales-Backen, M. A., Bámaca, M. Y., \& Zeiders, K. H. (2009). Latino adolescents' academic success: The role of discrimination, academic motivation, and gender. Journal of Adolescence, 32(4), 941-962. https://doi.org/ 10.1016/j.adolescence.2008.08.007

American Psychiatric Association. (2013). Diagnostic and Statistical Manual of Mental Disorders (5th edition). American Psychiatric Association. https://doi.org/10.1176/appi.books.9780890425596

Asbury, K., Fox, L., Deniz, E., Code, A., \& Toseeb, U. (2021). How is COVID-19 affecting the mental health of children with special educational needs and disabilities and their families? Journal of Autism and Developmental Disorders, 51(5), 1772-1780. https:// doi.org/10.1007/s10803-020-04577-2

Assor, A., Kaplan, H., \& Roth, G. (2002). Choice is good, but relevance is excellent: Autonomy-enhancing and suppressing teacher behaviours predicting students' engagement in schoolwork. British Journal of Educational Psychology, 72, 261-278.

Barry, J. G., Yasin, I., \& Bishop, D. V. M. (2007). Heritable risk factors associated with language impairments. Genes, Brain and
Behavior, 6(1), 66-76. https://doi.org/10.1111/j.1601-183X. 2006.00232.x

Barry, T. D., Lyman, R. D., \& Klinger, L. G. (2002). Academic underachievement and Attention-Deficit/Hyperactivity Disorder. Journal of School Psychology, 40(3), 259-283. https://doi.org/10. 1016/S0022-4405(02)00100-0

Baschenis, I. M. C., Farinotti, L., Zavani, E., Grumi, S., Bernasconi, P., Rosso, E., Provenzi, L., Borgatti, R., Termine, C., \& Chiappedi, M. (2021). Reading skills of children with dyslexia improved less than expected during the COVID-19 lockdown in Italy. Children, 8(7), 560. https://doi.org/10.3390/children8070560

Baten, E., \& Desoete, A. (2018). Mathematical (dis)abilities within the Opportunity-Propensity Model: The choice of math test matters. Frontiers in Psychology, 9, 667. https://doi.org/10.3389/fpsyg. 2018.00667

Baten, E., Vansteenkiste, M., De Muynck, G.-J., De Poortere, E., $\&$ Desoete, A. (2020). How can the blow of math difficulty on elementary school children's motivational, cognitive, and affective experiences be dampened? The critical role of autonomy-supportive instructions. Journal of Educational Psychology, 112(8), 1490-1505. https://doi.org/10.1037/edu0000444

Baumgartner, D., Bryan, T., Donahue, M., \& Nelson, C. (1993). Thanks for asking: Parent comments about homework, tests, and grades. Exceptionality, 4(3), 177-185. https://doi.org/10. 1207/s15327035ex0403_3

Becker, S. P., Breaux, R., Cusick, C. N., Dvorsky, M. R., Marsh, N. P., Sciberras, E., \& Langberg, J. M. (2020). Remote learning During COVID-19: Examining school practices, service continuation, and difficulties for adolescents with and without Attention-Deficit/Hyperactivity Disorder. Journal of Adolescent Health, 67(6), 769-777. https://doi.org/10.1016/j.jadoh ealth.2020.09.002

Bentenuto, A., Mazzoni, N., Giannotti, M., Venuti, P., \& de Falco, S. (2021). Psychological impact of COVID-19 pandemic in Italian families of children with neurodevelopmental disorders. Research in Developmental Disabilities, 109, 103840. https:// doi.org/10.1016/j.ridd.2020.103840

Berkeley, S., \& Larsen, A. (2018). Fostering self-regulation of students with learning disabilities: Insights from 30 years of reading comprehension intervention research. Learning Disabilities Research \& Practice, 33(2), 75-86. https://doi.org/10.1111/ldrp.12165

Blank, R., Barnett, A. L., Cairney, J., Green, D., Kirby, A., Polatajko, H., Rosenblum, S., Smits-Engelsman, B., Sugden, D., Wilson, P., \& Vinçon, S. (2019). International clinical practice recommendations on the definition, diagnosis, assessment, intervention, and psychosocial aspects of developmental coordination disorder. Developmental Medicine and Child Neurology, 61(3), 242-285. https://doi.org/10.1111/dmcn.14132

Brouse, C. H., Basch, C. E., Leblanc, M., McKnight, K. R., \& Lei, T. (2010). College students' academic motivation: Differences by gender, class, and source of payment. College Quarterly, 13(1), $1-10$.

Bryan, T., \& Burstein, K. (2004). Improving homework completion and academic performance: Lessons from special education. Theory into Practice, 43(3), 213-219. https://doi.org/10.1353/ tip.2004.0030

Byrnes, J. P. (2020). The potential utility of an opportunity-propensity framework for understanding individual and group differences in developmental outcomes: A retrospective progress report. Developmental Review, 56, 100911. https://doi.org/10.1016/j. dr.2020.100911

Byrnes, J. P., \& Miller-Cotto, D. (2016). The growth of mathematics and reading skills in segregated and diverse schools: An opportunity-propensity analysis of a national database. Contemporary Educational Psychology, 46, 34-51. https://doi.org/10.1016/j. cedpsych.2016.04.002 
Byrnes, J. P., \& Miller, D. C. (2007). The relative importance of predictors of math and science achievement: An opportunity-propensity analysis. Contemporary Educational Psychology, 32(4), 599-629. https://doi.org/10.1016/j.cedpsych.2006.09.002

Byrnes, J. P., \& Wasik, B. A. (2009). Factors predictive of mathematics achievement in kindergarten, first and third grades: An opportunity-propensity analysis. Contemporary Educational Psychology, 34(2), 167-183. https://doi.org/10.1016/j.cedpsych.2009.01.002

Cao, W., Fang, Z., Hou, G., Han, M., Xu, X., Dong, J., \& Zheng, J. (2020). The psychological impact of the COVID-19 epidemic on college students in China. Psychiatry Research, 287, 112934. https://doi.org/10.1016/J.PSYCHRES.2020.112934

Carrington, S., Saggers, B., Webster, A., Harper-Hill, K., \& Nickerson, J. (2020). What Universal Design for Learning principles, guidelines, and checkpoints are evident in educators' descriptions of their practice when supporting students on the autism spectrum? International Journal of Educational Research. https://doi.org/ 10.1016/j.ijer.2020.101583

Chan, R. C. H., \& Fung, S. C. (2021). Elevated levels of COVID19-related stress and mental health problems among parents of children with developmental disorders during the pandemic. Journal of Autism and Developmental Disorders, 2021, 1-12. https://doi.org/10.1007/S10803-021-05004-W

Chen, Q., Kong, Y., Gao, W., \& Mo, L. (2018). Effects of socioeconomic status, parent-child relationship, and learning motivation on reading ability. Frontiers in Psychology, 9, 1297. https://doi. org/10.3389/fpsyg.2018.01297

Cheon, S. H., Reeve, J., \& Vansteenkiste, M. (2020). When teachers learn how to provide classroom structure in an autonomysupportive way: Benefits to teachers and their students. Teaching and Teacher Education, 90, 103004. https://doi.org/10.1016/j. tate.2019.103004

Colizzi, M., Sironi, E., Antonini, F., Ciceri, M. L., Bovo, C., \& Zoccante, L. (2020). Psychosocial and behavioral impact of COVID19 in autism spectrum disorder: An online parent survey. Brain Sciences. https://doi.org/10.3390/brainsci10060341

Cooper, H., Robinson, J. C., \& Patall, E. A. (2006). Does homework improve academic achievement? A synthesis of research, 19872003. Review of Educational Research, 76(1), 1-62. https://doi. org/10.3102/00346543076001001

Cooper, H., \& Valentine, J. C. (2001). Using research to answer practical questions about homework. Educational Psychologist, 36(3), 143-153. https://doi.org/10.1207/S15326985EP3603_1

D’Angiulli, A., Siegel, L. S., \& Hertzman, C. (2004). Schooling, socioeconomic context and literacy development. Educational Psychology, 24(6), 867-883. https://doi.org/10.1080/0144341042 000271746

da Rosa Piccolo, L., Arteche, A. X., Fonseca, R. P., Grassi-Oliveira, R., \& Salles, J. F. (2016). Influence of family socioeconomic status on IQ, language, memory and executive functions of Brazilian children. Psicologia: Reflexao e Critica, 29(1), 1-10. https://doi. org/10.1186/s41155-016-0016-x

Daley, D., \& Birchwood, J. (2010). ADHD and academic performance: Why does ADHD impact on academic performance and what can be done to support ADHD children in the classroom? Child Care: Health and Development, 36(4), 455-464. https://doi.org/ 10.1111/j.1365-2214.2009.01046.x

De Naeghel, J., Van Keer, H., Vansteenkiste, M., Haerens, L., \& Aelterman, N. (2016). Promoting elementary school students' autonomous reading motivation: Effects of a teacher professional development workshop. The Journal of Educational Research, 109(3), 232-252. https://doi.org/10.1080/00220671.2014.942032

De Naeghel, J., Van Keer, H., Vansteenkiste, M., \& Rosseel, Y. (2012). The relation between elementary students' recreational and academic reading motivation, reading frequency, engagement, and comprehension: A self-determination theory perspective. Journal of Educational Psychology, 104(4), 1006-1021. https://doi.org/ 10.1037/a0027800

De Weerdt, F., Desoete, A., \& Roeyers, H. (2013). Working memory in children with reading disabilities and/or mathematical disabilities. Journal of Learning Disabilities, 46(5), 461-472. https:// doi.org/10.1177/0022219412455238

Desforges, C., \& Abouchaar, A. (2003). The impact of parental involvement, parental support and family education on pupil achievements and adjustment: A literature review (Research report 433).

Desoete, A., \& Warreyn, P. (2020). Introduction to the special issue: Mathematical abilities in developmental disabilities. Research in Developmental Disabilities, 107, 103805. https://doi.org/10. 1016/j.ridd.2020.103805

Dewey, D. (2018). What is comorbidity and why does it matter in neurodevelopmental disorders? Current Developmental Disorders Reports, 5(4), 235-242. https://doi.org/10.1007/ s40474-018-0152-3

Diamantopoulou, S., Rydell, A. M., Thorell, L. B., \& Bohlin, G. (2007). Impact of executive functioning and symptoms of attention deficit hyperactivity disorder on children's peer relations and school performance. Developmental Neuropsychology, 32(1), 521-542. https://doi.org/10.1080/87565640701360981

Dong, C., Cao, S., \& Li, H. (2020). Young children's online learning during COVID-19 pandemic: Chinese parents' beliefs and attitudes. Children and Youth Services Review, 118, 105440. https:// doi.org/10.1016/j.childyouth.2020.105440

Dowker, A. (2020). Arithmetic in developmental cognitive disabilities. Research in Developmental Disabilities, 107, 103778. https://doi org/10.1016/j.ridd.2020.103778

Doyle, A. E. (2006). Executive functions in attention-deficit/hyperactivity disorder. Journal of Clinical Psychiatry, 67(8), 21-26.

Dugdale, A.-S., Thompson, A. R., Leedham, A., Beail, N., \& Freeth, M. (2021). Intense connection and love: The experiences of autistic mothers. Autism, 25(7), 1973-1984. https://doi.org/10. $1177 / 13623613211005987$

DuPaul, G. J., \& Stoner, G. (2003). ADHD in the schools: Assessment and intervention strategies (2nd ed.). Guilford Press.

Duppong Hurley, K., Lambert, M. C., January, S. A. A., \& Huscroft D’Angelo, J. (2017). Confirmatory factor analyses comparing parental involvement frameworks with secondary students. Psychology in the Schools, 54(9), 947-964. https://doi.org/10.1002/ PITS.22039

Elmer, T., Mepham, K., \& Stadtfeld, C. (2020). Students under lockdown: Comparisons of students' social networks and mental health before and during the COVID-19 crisis in Switzerland. PLoS ONE, 15(7), e0236337. https://doi.org/10.1371/JOURN AL.PONE.0236337

Enders, C. K., \& Bandalos, D. L. (2001). The relative performance of full information maximum likelihood estimation for missing data in structural equation models. Structural Equation Modeling, 8(3), 430-457. https://doi.org/10.1207/S15328007SEM0803_5

Engzell, P., Frey, A., \& Verhagen, M. D. (2021). Learning loss due to school closures during the COVID-19 pandemic. Proceedings of the National Academy of Sciences. https://doi.org/10.1073/ PNAS. 2022376118

Feinstein, L., Symons, J., Feinstein, L., \& Symons, J. (1999). Attainment in secondary school. Oxford Economic Papers, 51(2), 300-321.

Fitzpatrick, B. R., Berends, M., Ferrare, J. J., \& Waddington, R. J. (2020). Virtual illusion: Comparing student achievement and teacher and classroom characteristics in online and brick-andmortar charter schools. Educational Researcher, 49(3), 161-175. https://doi.org/10.3102/0013189X20909814 
Forteza-Forteza, D., Rodríguez-Martín, A., Álvarez-Arregui, E., \& Álvarez-Hevia, D. M. (2021). Inclusion, dyslexia, emotional state and learning: Perceptions of Ibero-American children with dyslexia and their parents during the COVID-19 lockdown. Sustainability, 13(5), 2739. https://doi.org/10.3390/SU13052739

Friedrich, A., Moning, J., Weiss, J., \& Schlarb, A. A. (2017). The effects of parental ADHD symptoms on parenting behaviors. Health, 9(7), 1054-1074. https://doi.org/10.4236/health.2017. 97077

Giusti, L., Mammarella, S., Salza, A., Del Vecchio, S., Ussorio, D., Casacchia, M., \& Roncone, R. (2021). Predictors of academic performance during the covid-19 outbreak: impact of distance education on mental health, social cognition and memory abilities in an Italian university student sample. BMC Psychology, 9(1), 1-17. https://doi.org/10.1186/S40359-021-00649-9

Gnambs, T., \& Hanfstingl, B. (2016). The decline of academic motivation during adolescence: An accelerated longitudinal cohort analysis on the effect of psychological need satisfaction. Educational Psychology, 36(9), 1691-1705. https://doi.org/10.1080/ 01443410.2015 .1113236

Gore, J., Fray, L., Miller, A., Harris, J., \& Taggart, W. (2021). The impact of COVID-19 on student learning in New South Wales primary schools: An empirical study. The Australian Educational Researcher, 2021, 1-33. https://doi.org/10.1007/ S13384-021-00436-W

Grigorenko, E. L., Compton, D. L., Fuchs, L. S., Wagner, R. K., Willcutt, E. G., \& Fletcher, J. M. (2019). Understanding, educating, and supporting children with specific learning disabilities: 50 years of science and practice. American Psychologist, 75(1), 37. https://doi.org/10.1037/amp0000452

Hammerstein, S., König, C., Dreisörner, T., \& Frey, A. (2021). Effects of COVID-19-related school closures on student achievement: A systematic review. Frontiers in Psychology, 12, 4020. https:// doi.org/10.3389/fpsyg.2021.746289

Harpin, V. A. (2005). The effect of ADHD on the life of an individual, their family, and community from preschool to adult life. Archives of Disease in Childhood. https://doi.org/10.1136/adc. 2004.059006

Harris, A., \& Goodall, J. (2008). Do parents know they matter? Engaging all parents in learning. Educational Research, 50(3), 277289. https://doi.org/10.1080/00131880802309424

Hattie, J. (2008). Visible learning: A synthesis of over 800 meta-analyses relating to achievement. In Visible Learning: A Synthesis of Over 800 Meta-Analyses Relating to Achievement. Routledge Taylor \& Francis Group. https://doi.org/10.4324/9780203887332

Haug, N., Geyrhofer, L., Londei, A., Dervic, E., Desvars-Larrive, A., Loreto, V., Pinior, B., Thurner, S., \& Klimek, P. (2020). Ranking the effectiveness of worldwide COVID-19 government interventions. Nature Human Behaviour, 4(12), 1303-1312. https://doi. org/10.1038/s41562-020-01009-0

Hill, N. E., \& Tyson, D. F. (2009). Parental involvement in middle school: A meta-analytic assessment of the strategies that promote achievement. Developmental Psychology, 45(3), 740-763. https://doi.org/10.1037/a0015362

Hoover-Dempsey, K. V., \& Sandler, H. M. (1997). Why do parents become involved in their children's education? Review of Educational Research, 67(1), 3. https://doi.org/10.2307/1170618

Hu, L., \& Bentler, P. M. (1999). Cutoff criteria for fit indexes in covariance structure analysis: Conventional criteria versus new alternatives. Structural Equation Modeling: A Multidisciplinary Journal, 6(1), 1-55. https://doi.org/10.1080/10705519909540118

Huemer, S. V., \& Mann, V. (2010). A comprehensive profile of decoding and comprehension in autism spectrum disorders. Journal of Autism and Developmental Disorders, 40(4), 485-493. https:// doi.org/10.1007/s10803-009-0892-3
Imeraj, L., Antrop, I., Sonuga-Barke, E., Deboutte, D., Deschepper, E., Bal, S., \& Roeyers, H. (2013). The impact of instructional context on classroom on-task behavior: A matched comparison of children with ADHD and non-ADHD classmates. Journal of School Psychology, 51(4), 487-498. https://doi.org/10.1016/j. jsp.2013.05.004

Ingersoll, B., \& Berger, N. I. (2015). Parent engagement with a telehealth-based parent-mediated intervention program for children with autism spectrum disorders: Predictors of program use and parent outcomes. Journal of Medical Internet Research. https:// doi.org/10.2196/jmir.4913

Jang, H. (2008). Supporting students' motivation, engagement, and learning during an uninteresting activity. Journal of Educational Psychology, 100(4), 798-811. https://doi.org/10.1037/a0012841

Johnston, C., Mash, E. J., Miller, N., \& Ninowski, J. E. (2012). Parenting in adults with attention-deficit/hyperactivity disorder (ADHD). In Clinical Psychology Review (Vol. 32, Issue 4, pp. 215-228). Pergamon. https://doi.org/10.1016/j.cpr.2012.01.007

Jokić, C. S., \& Whitebread, D. (2010). The role of self-regulatory and metacognitive competence in the motor performance difficulties of children with Developmental Coordination Disorder: A theoretical and empirical review. Educational Psychology Review, 23(1), 75-98. https://doi.org/10.1007/ S10648-010-9148-1

Karst, J. S., \& van Hecke, A. V. (2012). Parent and family impact of Autism Spectrum Disorders: A review and proposed model for intervention evaluation. In Clinical Child and Family Psychology Review (Vol. 15, Issue 3, pp. 247-277). Springer. https:// doi.org/10.1007/s10567-012-0119-6

Kaya, M., \& Selvitopu, A. (2019). A meta-analysis of the effects of some factors on teachers' classroom management skills. International Journal of Contemporary Educational Research, 6(2), 409-425. https://doi.org/10.33200/ijcer.621313

Kennette, L. N., \& Wilson, N. A. (2019). Universal Design for Learning (UDL). Journal of Effective Teaching in Higher Education, 2(1), 1-26. https://doi.org/10.36021/jethe.v2i1.17

Klingner, J. K., \& Vaughn, S. (1999). Students' perceptions of instruction in inclusion classrooms: Implications for students with Learning Disabilities. Exceptional Children, 66(1), 23-37. https://doi.org/10.1177/001440299906600102

Kong, M. (2021). What COVID-19 means for non-neurotypical children and their families. In Pediatric Research (Vol. 89, Issue 3, pp. 396-397). Springer Nature. https://doi.org/10.1038/ s41390-020-0913-7

Korzekwa, P. (2012). Improving homework performance and independence in students with autism spectrum disorders through self-management and parents as interventionists. In Dissertation Abstracts International Section A: Humanities and Social Sciences (Vol. 72, Issues 10-A).

Latzer, I., Leitner, Y., \& Karnieli-Miller, O. (2021). Core experiences of parents of children with autism during the COVID19 pandemic lockdown. Autism, 25(4), 1047-1059. https://doi. org/10.1177/1362361320984317

Lee, J.-S., \& Bowen, N. K. (2006). Parent involvement, cultural capital, and the achievement gap among elementary school children. American Educational Research Journal, 43(2), 193-218. https://doi.org/10.3102/00028312043002193

Lewis, R. W., \& Farkas, G. (2017). Using an opportunity-propensity framework to estimate individual-, classroom-, and schoollevel predictors of middle school science achievement. Contemporary Educational Psychology, 51, 185-197. https://doi. org/10.1016/j.cedpsych.2017.08.003

Liu, J., Peng, P., \& Luo, L. (2020). The relation between family socioeconomic status and academic achievement in China: A meta-analysis. Educational Psychology Review, 32(1), 49-76. https://doi.org/10.1007/s10648-019-09494-0 
Loe, I. M., \& Feldman, H. M. (2007). Academic and educational outcomes of children with ADHD. Journal of Pediatric Psychology, 32(6), 643-654. https://doi.org/10.1093/jpepsy/js1054

Logan, S., \& Medford, E. (2011). Gender differences in the strength of association between motivation, competency beliefs and reading skill. Educational Research, 53(1), 85-94. https://doi. org/10.1080/00131881.2011.552242

Maguire, R., Brunner, R., Stalker, K., \& Mitchell, J. (2009). Disabled parents' involvement in their children's education: An examination of good practice. http://www.cfbt.com/evidenceforeduc ation/pdf/4.2500_DPReport_5.pdf.

Maity, S., Sahu, T. N., \& Sen, N. (2021). Panoramic view of digital education in COVID-19: A new explored avenue. Review of Education, 9(2), 405-423. https://doi.org/10.1002/REV3.3250

Maldonado, J. E., \& De Witte, K. (2021). The effect of school closures on standardised student test outcomes. British Educational Research Journal. https://doi.org/10.1002/berj.3754

Maríñez-Lora, A. M., \& Quintana, S. M. (2009). Low-income urban African American and Latino parents' school involvement: Testing a theoretical model. School Mental Health, 1(4), 212-228. https://doi.org/10.1007/s12310-009-9015-8

Marks, G. N. (2016). The relative effects of socio-economic, demographic, non-cognitive and cognitive influences on student achievement in Australia. Learning and Individual Differences, 49, 1-10. https://doi.org/10.1016/j.lindif.2016.05.012

Marks, G. N. (2017). Is SES really that important for educational outcomes in Australia? A review and some recent evidence. Australian Educational Researcher, 44(2), 191-211. https://doi.org/10. 1007/s13384-016-0219-2

Martin, A. J., \& Lazendic, G. (2018). Achievement in large-scale national numeracy assessment: An ecological study of motivation and student, home, and school predictors. Journal of Educational Psychology, 110(4), 465-482. https://doi.org/10.1037/ EDU0000231

Mercader, J., Miranda, A., Presentación, M. J., Siegenthaler, R., \& Rosel, J. F. (2018). Contributions of motivation, early numeracy skills, and executive functioning to mathematical performance. A Longitudinal Study. Frontiers in Psychology, 8, 2375. https:// doi.org/10.3389/fpsyg.2017.02375

Miller, P., Hazan-Liran, B., \& Cohen, D. (2019). Does task-irrelevant colour information create extraneous cognitive load? Evidence from a learning task. Quarterly Journal of Experimental Psychology, 72(5), 1155-1163. https://doi.org/10.1177/1747021818 781425

Montague, M. (2008). Self-regulation strategies to improve mathematical problem solving for students with Learning Disabilities. Learning Disability Quarterly, 31(1), 37-44. https://doi.org/10. 2307/30035524

Morris, J. (2003). Supporting disabled adults in their parenting role. Joseph Rowntree Foundation. https://www.jrf.org.uk/report/ supporting-disabled-adults-their-parenting-role-0.

Mulligan, S. (2001). Classroom strategies used by teachers of students with Attention Deficit Hyperactivity Disorder. Physical \& Occupational Therapy in Pediatrics, 20(4), 25-44. https://doi.org/10. 1080/j006v20n04_03

Murphy, A., Pinkerton, L. M., Bruckner, E., \& Risser, H. J. (2021). The impact of the novel Coronavirus Disease 2019 on therapy service delivery for children with disabilities. The Journal of Pediatrics, 231, 168-177.e1. https://doi.org/10.1016/j.jpeds.2020.12.060

Niemiec, C. P., \& Coulson, J. C. (2017). Need-supportive parenting and its role in the wellbeing and recovery of individuals: A selfdetermination theory perspective. Wellbeing, Recovery and Mental Health. https://doi.org/10.1017/9781316339275.025

Niemiec, C. P., \& Ryan, R. M. (2009). Autonomy, competence, and relatedness in the classroom: Applying self-determination theory to educational practice. Theory and Research in Education, 7(2), 133-144. https://doi.org/10.1177/1477878509104318

Nonweiler, J., Rattray, F., Baulcomb, J., Happé, F., \& Absoud, M. (2020). Prevalence and associated factors of emotional and behavioural difficulties during COVID-19 pandemic in children with neurodevelopmental disorders. Children, 7(9), 128. https:// doi.org/10.3390/children7090128

Olson, R. (2011). Genetic and environmental influences on phonological abilities and reading achievement. In S. A. Brady, D. Braze, \& C. A. Fowler (Eds.), New directions in communication disorders research. Explaining individual differences in reading: Theory and evidence (pp. 197-216). Psychology Press.

Owens, M., Stevenson, J., Hadwin, J. A., \& Norgate, R. (2012). Anxiety and depression in academic performance: An exploration of the mediating factors of worry and working memory. School Psychology International, 33(4), 433-449. https://doi.org/10.1177/ 0143034311427433

Ozonoff, S., South, M., \& Provencal, S. (2007). Executive functions in autism: Theory and practice. In J. M. Pérez, P. M. González, M. Llorente Comí, \& C. Nieto (Eds.), New developments in autism: The future is today (pp. 185-213). Jessica Kingsley Publishers.

Park, S., \& Holloway, S. D. (2013). No parent left behind: Predicting parental involvement in adolescents' education within a sociodemographically diverse population. The Journal of Educational Research, 106(2), 105-119. https://doi.org/10.1080/00220671. 2012.667012

Peng, P., Wang, T., Wang, C., \& Lin, X. (2019). A meta-analysis on the relation between fluid intelligence and reading/mathematics: Effects of tasks, age, and social economics status. Psychological Bulletin, 145(2), 189-236. https://doi.org/10.1037/bul0000182

Peterson, R. L., \& Pennington, B. F. (2015). Developmental dyslexia. Annual Review of Clinical Psychology, 11, 283-307. https://doi. org/10.1146/annurev-clinpsy-032814-112842

Pieters, S., Desoete, A., Van Waelvelde, H., Vanderswalmen, R., \& Roeyers, H. (2012). Mathematical problems in children with developmental coordination disorder. Research in Developmental Disabilities, 33(4), 1128-1135. https://doi.org/10.1016/j.ridd. 2012.02.007

Putwain, D. W., Connors, L., \& Symes, W. (2010). Do cognitive distortions mediate the test anxiety-examination performance relationship? Educational Psychology, 30(1), 11-26. https://doi.org/10. 1080/01443410903328866

R Core Team. (2020). R: A language and environment for statistical computing. R Foundation for Statistical Computing. https:// www.r-project.org/.

Raggi, V. L., \& Chronis, A. M. (2006). Interventions to address the academic impairment of children and adolescents with ADHD. Clinical Child and Family Psychology Review, 9(2), 85-111. https://doi.org/10.1007/s10567-006-0006-0

Rajkumar, R. P. (2020). COVID-19 and mental health: A review of the existing literature. Asian Journal of Psychiatry, 52, 102066. https://doi.org/10.1016/J.AJP.2020.102066

Reeve, J. (2009). Why teachers adopt a controlling motivating style toward students and how they can become more autonomy supportive. Educational Psychologist, 44(3), 159-175. https://doi. org/10.1080/00461520903028990

Reeve, J. (2016). Autonomy-supportive teaching: What it is, how to do it. In Building Autonomous Learners (pp. 129-152). Singapore: Springer. https://doi.org/10.1007/978-981-287-630-0_7

Reeve, J., Jang, H., Hardre, P., \& Omura, M. (2002). Providing a rationale in an autonomy-supportive way as a strategy to motivate others during an uninteresting activity. Motivation and Emotion, 26(3), 183-207. https://doi.org/10.1023/A:1021711629417

Reich, J., Buttimer, C., Fang, A., Hillaire, G., Hirsch, K., Larke, L., Littenberg-Tobias, J., Moussapour, R. M., Napier, A., Thompson, M., \& Slama, R. (2020). Remote learning guidance from state 
education agencies during the COVID-19 pandemic: A first look. https://doi.org/10.35542/osf.io/437e2

Rodríguez-Hernández, C. F., Cascallar, E., \& Kyndt, E. (2020). Socioeconomic status and academic performance in higher education: A systematic review. Educational Research Review, 29, 100305. https://doi.org/10.1016/j.edurev.2019.100305

Rodríguez-Hidalgo, A. J., Pantaleón, Y., Dios, I., \& Falla, D. (2020). Fear of COVID-19, stress, and anxiety in university undergraduate students: A predictive model for depression. Frontiers in Psychology, 11, 3041. https://doi.org/10.3389/fpsyg.2020.591797

Rodriguez, A., Järvelin, M. R., Obel, C., Taanila, A., Miettunen, J., Moilanen, I., Henriksen, T. B., Pietiläinen, K., Ebeling, H., Kotimaa, A. J., Linnet, K. M., \& Olsen, J. (2007). Do inattention and hyperactivity symptoms equal scholastic impairment? Evidence from three European cohorts. BMC Public Health. https://doi. org/10.1186/1471-2458-7-327

Rosseel, Y. (2012). Lavaan: An R package for Structural Equation Modeling. Journal of Statistical Software, 48(2), 1-36. https:// doi.org/10.18637/jss.v048.i02

Rutgers, A. H., Van IJzendoorn, M. H., Bakermans-Kranenburg, M. J., Swinkels, S. H. N., Van Daalen, E., Dietz, C., Naber, F. B. A., Buitelaar, J. K., \& Van Engeland, H. (2007). Autism, attachment and parenting: A comparison of children with autism spectrum disorder, mental retardation, language disorder, and non-clinical children. Journal of Abnormal Child Psychology, 35(5), 859870. https://doi.org/10.1007/s10802-007-9139-y

Ryan, R., \& Connell, J. (1989). Perceived locus of causality and internalization: Examining reasons for acting in two domains. Journal of Personality and Social Psychology, 57(5), 749-761. https:// doi.org/10.1037/0022-3514.57.5.749

Ryan, R., \& Deci, E. (2000). Self-determination theory and the facilitation of intrinsic motivation, social development, and well-being. The American Psychologist, 55(1), 68-78. https://doi.org/10. 1037/0003-066X.55.1.68

Ryan, R., \& Deci, E. (2017). Self-determination theory. Basic psychological needs in motivation, development and wellness. Guilford Press.

Salend, S. J., \& Schliff, J. (1989). An examination of the homework practices of teachers of students with learning disabilities. Journal of Learning Disabilities, 22(10), 621-623. https://doi.org/10. 1177/002221948902201006

Saravanan, C., Mahmoud, I., Elshami, W., \& Taha, M. H. (2020). Knowledge, anxiety, fear, and psychological distress about COVID-19 among university students in the United Arab Emirates. Frontiers in Psychiatry, 11, 1057. https://doi.org/10.3389/ fpsyt.2020.582189

Schermelleh-Engel, K., Moosbrugger, H., \& Müller, H. (2003). Evaluating the fit of structural equation models: Tests of significance and descriptive goodness-of-fit measures. In Methods of Psychological Research Online (Vol. 8, Issue 2).

Sibley, M. H., Altszuler, A. R., Morrow, A. S., \& Merrill, B. M. (2014). Mapping the academic problem behaviors of adolescents with ADHD. School Psychology Quarterly, 29(4), 422-437. https:// doi.org/10.1037/spq0000071

Smith, J., Guimond, F.-A., Bergeron, J., St-Amand, J., Fitzpatrick, C., \& Gagnon, M. (2021). Changes in students' achievement motivation in the context of the COVID-19 pandemic: A function of extraversion/introversion? Education Sciences, 11(1), 30. https:// doi.org/10.3390/educsci11010030

Snowling, M. J., \& Melby-Lervåg, M. (2016). Oral language deficits in familial dyslexia: A meta-analysis and review. Psychological Bulletin, 142(5), 498-545. https://doi.org/10.1037/bul0000037

Soenens, B., Sierens, E., Vansteenkiste, M., Dochy, F., \& Goossens, L. (2012). Psychologically controlling teaching: Examining outcomes, antecedents, and mediators. Journal of Educational Psychology, 104(1), 108-120. https://doi.org/10.1037/a0025742
Sonuga-Barke, E. J. S., Daley, D., \& Thompson, M. (2002). Does maternal ADHD reduce the effectiveness of parent training for preschool children's ADHD? Journal of the American Academy of Child and Adolescent Psychiatry, 41(6), 696-702. https://doi. org/10.1097/00004583-200206000-00009

Soriano-Ferrer, M., Morte-Soriano, M. R., Begeny, J., \& Piedra-Martínez, E. (2021). Psychoeducational challenges in Spanish children with dyslexia and their parents' stress during the COVID-19 pandemic. Frontiers in Psychology, 12, 2005. https://doi.org/10. 3389/FPSYG.2021.648000

St Clair, M. C., Forrest, C. L., Yew, S. G. K., \& Gibson, J. L. (2019). Early risk factors and emotional difficulties in children at risk of developmental language disorder: A population cohort study. Journal of Speech, Language, and Hearing Research, 62(8), 2750-2771. https://doi.org/10.1044/2018_JSLHR-L-18-0061

Steingut, R. R., Patall, E. A., \& Trimble, S. S. (2017). The effect of rationale provision on motivation and performance outcomes: A meta-analysis. Motivation Science, 3(1), 19-50. https://doi.org/ 10.1037/mot0000039

Tarleton, B., Ward, L., \& Howarth, J. (2005). Finding the right support? A review of issues and positive practice in supporting people with learning difficulties and their children. The Baring Foundation.

Thapar, A., Cooper, M., Eyre, O., \& Langley, K. (2013). Practitioner review: What have we learnt about the causes of ADHD? Journal of Child Psychology and Psychiatry, 54(1), 3-16. https://doi.org/ 10.1111/j.1469-7610.2012.02611.x

Theiling, J., \& Petermann, F. (2016). Neuropsychological profiles on the WAIS-IV of adults with ADHD. Journal of Attention Disorders, 20(11), 913-924. https://doi.org/10.1177/1087054713 518241

Thorell, L. B. (2007). Do delay aversion and executive function deficits make distinct contributions to the functional impact of ADHD symptoms? A study of early academic skill deficits. Journal of Child Psychology and Psychiatry and Allied Disciplines, 48(11), 1061-1070. https://doi.org/10.1111/j.1469-7610.2007.01777.x

Tick, B., Bolton, P., Happé, F., Rutter, M., \& Rijsdijk, F. (2016). Heritability of autism spectrum disorders: A meta-analysis of twin studies. Journal of Child Psychology and Psychiatry and Allied Disciplines, 57(5), 585-595. https://doi.org/10.1111/jcpp.12499

Titeca, D., Roeyers, H., Loeys, T., Ceulemans, A., \& Desoete, A. (2015). Mathematical abilities in elementary school children with Autism Spectrum Disorder. Infant and Child Development, 24(6), 606-623. https://doi.org/10.1002/icd.1909

Vansteenkiste, M., Lens, W., \& Deci, E. L. (2006). Intrinsic versus extrinsic goal contents in Self-Determination Theory: Another look at the quality of academic motivation. Educational Psychologist, 41(1), 19-31. https://doi.org/10.1207/s15326985ep4101_4

Vansteenkiste, M., Ryan, R. M., \& Soenens, B. (2020). Basic psychological need theory: Advancements, critical themes, and future directions. Motivation and Emotion, 44(1), 1-31. https://doi.org/ 10.1007/s11031-019-09818-1

Walker, M., Dewald, A., \& Sinnett, S. (2014). The role of modality congruence in the presentation and recognition of task-irrelevant stimuli in dual task paradigms. In P. Bello, M. Guarini, M. McShane, \& B. Scassellati (Eds.), Proceedings of the 36th Annual Conference of the Cognitive Science Society (pp. 17361741). Cognitive Science Society.

Wang, A. H., Shen, F., \& Byrnes, J. P. (2013). Does the OpportunityPropensity Framework predict the early mathematics skills of low-income pre-kindergarten children? Contemporary Educational Psychology, 38(3), 259-270. https://doi.org/10.1016/j. cedpsych.2013.04.004

White, S. W., Stoppelbein, L., Scott, H., \& Spain, D. (2021). It took a pandemic: Perspectives on impact, stress, and telehealth from caregivers of people with autism. Research in Developmental 
Disabilities, 113, 103938. https://doi.org/10.1016/j.ridd.2021. 103938

WHO. (2020). Coronavirus disease (COVID-19): Situation Report-202. https://www.who.int/docs/default-source/coronaviru se/situation-reports/20200809-covid-19-sitrep-202.pdf?sfvrsn= 2c7459f6_2.

Willcutt, E. G., Pennington, B. F., Duncan, L., Smith, S. D., Keenan, J. M., Wadsworth, S., Defries, J. C., \& Olson, R. K. (2010). Understanding the complex etiologies of developmental disorders: Behavioral and molecular genetic approaches. Journal of Developmental and Behavioral Pediatrics, 31(7), 533-544. https://doi.org/10.1097/DBP.0b013e3181ef42a1

Xu, J. (2011). Homework completion at the secondary school level: A multilevel analysis. The Journal of Educational Research, 104(3), 171-182. https://doi.org/10.1080/00220671003636752

Zaccoletti, S., Camacho, A., Correia, N., Aguiar, C., Mason, L., Alves, R. A., \& Daniel, J. R. (2020). Parents' perceptions of student academic motivation during the COVID-19 lockdown: A crosscountry comparison. Frontiers in Psychology. https://doi.org/10. 3389/FPSYG.2020.592670
Zawadka, J., Miękisz, A., Nowakowska, I., Plewko, J., Kochańska, M., \& Haman, E. (2021). Remote learning among students with and without reading difficulties during the initial stages of the COVID-19 pandemic. Education and Information Technologies, 2021, 1-22. https://doi.org/10.1007/S10639-021-10559-3

Publisher's Note Springer Nature remains neutral with regard to jurisdictional claims in published maps and institutional affiliations. 